\title{
Wear resistance, oil resistance, morphology and vulcanization performances of ethylene-vinyl acetate/acrylonitrile butadiene rubber composites
}

\author{
B. C. Wang, H. He ${ }^{*}$ X. F. He, H. D. Chen, B. Huang
}

School of Materials Science and Engineering, South China University of Technology, Wushan Road, Tianhe District, 510640 Guangzhou City, Guangdong Province, China

\begin{abstract}
The composites consisting of ethylene-vinyl acetate rubber (EVM) and acrylonitrile butadiene rubber (NBR) were prepared by two-step blending method, and were reinforced with carbon black (CB) using 1,4-bis(tert-butylperoxyisopropyl) benzene (BIPB) as crosslinking agent. In addition, wear and oil resistance, morphology, vulcanization and dynamic mechanical properties of the composites were systematically investigated. 3D graph was used to analyze the trend of wear and oil resistance of the composites. SEM images showed that the wear mechanism of the composites was mainly abrasive wear, accompanied by fatigue wear. With the increase of NBR content, the wear resistance was effectively improved, which was revealed by the DIN abrasion volume, worn surfaces morphology and roughness. Meanwhile, the oil resistance was also improved according to the rate of volume change and surface contact angle. The EVM/NBR composites prepared by the two-step blending method showed higher $\Delta H$ (maximum torque $M_{\mathrm{H}}-$ minimum torque $M_{\mathrm{L}}$ ) than pristine EVM or NBR did. The composites containing $30 \mathrm{phr}$ of $\mathrm{CB}$ exhibited excellent wear and oil resistance, which broadened the applications field of the EVM/NBR composites.
\end{abstract}

Keywords: polymer composites, wear and oil resistance, morphology, vulcanization, two-step blending method

\section{Introduction}

EVM is the accepted abbreviation for ethylene-vinyl acetate copolymers with elastomeric properties and containing between 40 and $90 \%$ vinyl acetate (VA) [1]. It is also worth noticing that the substitution of some hydrogen atoms in the PE chain with vinyl acetate units disturb the regularity of the polymer chain structure. So the products with a different susceptibility to crystallization depend on the quantity of the VA combined in EVM [2]. EVM is a special rubber with good performance such as inherently excellent ozone resistance, good flexibility at low temperature, damping and mechanical properties, also, compatibility with inorganic materials, high heat resistance and hot-air aging resistance [3-6]. It is widely used in cables, rubber rollers, footwear, appliances in the automotive industry [1]. However, the main chain of EVM is saturated so that it can only be crosslinked with peroxide. It is strictly influenced the properties due to the presence of the heterogeneous network structure with densely crosslinked region and loosely crosslinked one, such as low tensile and tear strength. That is all as well as its physical and chemical properties, which easily leads to its unsatisfactory wear resistance [7-10]. Thus, the oil resistance is still not high enough despite of the high VA content in EVM [11]. These defects greatly limit the application of EVM, especially in the automotive, footwear and oil pipeline fields. Acrylonitrile butadiene rubber (NBR) has excellent oil and abrasion resistance because of

${ }^{*}$ Corresponding author, e-mail: pshuihe@scut.edu.cn

(C) BME-PT 
the strong electronegativity cyano and intermolecular forces [3]. However, it has some disadvantages in resistance to ozone, high and low temperatures and no self-reinforcing effect due to non-crystallization and unsaturated chain nature [12]. Blending with EVM and reinforcing fillers are expected to obtain the composites with excellent comprehensive properties to take into account the advantages of both [13].

The wear of rubber is a complex phenomenon and dependent on a combination of processes such as mechanical, mechanochemical and thermo-chemical [14]. The wear behavior of rubber can be commonly classified into three types, depending on the mechanism responsible for removal of material from the surface: (1) abrasive wear, (2) fatigue wear, and (3) curl wear [15]. The most severe wear is abrasive wear, caused by the occurrence of microcutting and longitudinal scratches from tearing on the tips of sharp asperities. It leads to the formation of a characteristic surface patterns, a series of parallel ridges lying perpendicular to the sliding direction [16]. Fatigue wear happens on the blunt asperities by cyclic deformation of the rubber, leading to a small cavitation and then propagation to a definite fracture. The curl wear occurs on a smooth surface by roll formation of the compressed rubber, which generates patterns detachment at the contact area. These patterns, known as Schallamach patterns, propagate across the contact zone from front to back [17]. Many researchers have studied the friction and wear properties of rubber composites. Schallamach [18] was the first to study the abrasion pattern of rubber surfaces in detail. Tangudom et al. [15] investigated the mechanical and wear behavior of natural rubber (NR), butadiene styrene rubber (SBR) and NR/SBR blends filled with silica hybrid filler.

Meanwhile, the polymer blending is a advantageous way to develop a novel polymer composite compared to synthesis of new polymers to meet the ever increasing performance demand [19]. Reinforcement by fillers, especially carbon black, is one of the most important aspects of polymer blending technology. Investigations on EVM/NBR composites have been reported by many research groups so far. Bhuyan et al. [20] fabricated 3D multi-walled carbon nanotube (MWCNT)/hectorite hybrid (HMH) nanofiller filled NBR/EVA nanocomposites. Results showed that mechanical properties are significantly improved with $\mathrm{HMH}$ content up to $4 \mathrm{wt} \%$ and best dynamic mechanical, dielectric response at 4 and $3 \mathrm{wt} \% \mathrm{HMH}$ content respectively. Varghese et al. [12] studied the effect of various crosslinking systems, the blend ratio, and various fillers on the mechanical properties of NBR/EVA blends. It was found that the peroxide shows the shortest cure time. The mechanical properties increase with the increment of EVA content. The reinforcing ability of the fillers is in the order of high-abrasion furnace black (HAF) $>$ semireinforcing furnace black $(\mathrm{SRF})>$ silica $>$ clay. Shi et al. [21] analysed the effects of polyvinyl chloride, chlorinated polyvinyl chloride, silica, carbon black, and phenolic resin on the mechanical and damping properties of EVM/NBR blends for the preparation of high damping materials. Shi and Bi [22] chose both sulphur and bis(tert-butyldioxyisopropyl) benzene (BIPB) as the curing agents to see the effect of PVC on the damping properties of EVM/NBR blends added in silica and so on.

However, the previous reports mainly focused on the effects of reinforcing fillers and vulcanization systems on the mechanical and damping properties of NBR/EVM composites, regularly using NBR as the main phase and EVM as the auxiliary phase by normal direct blending method. Yet systematical researching on wear and oil resistance of EVM/NBR composites have rarely been reported. EVM and NBR are complementary in structure and performance. In order to acquire the benefits of the two polymers, they can be blended together.

As we all know, it is difficult to disperse the ingredients in the rubber composites by the direct blending, resulting in unsatisfactory wear and oil resistance, mechanical and electrical properties. In this study, EVM/NBR compatible systems using BIPB as crosslinking agent and carbon black as reinforcing filler were fabricated by the simple two-step blending method, we studied the effects of NBR content on the wear and oil resistance, worn surfaces morphology, micro-morphology, vulcanization and dynamic mechanical properties of EVM/NBR composites.

\section{Experimental}

\subsection{Materials}

EVM (Levapren 500HV) with 50\% VA content, mooney viscosity $\mathrm{ML}(1+4) 100^{\circ} \mathrm{C} 25$, was obtained from LANXESS Co., Germany. NBR (NANCAR 1052 ) with $33 \%$ acrylonitrile content, mooney viscosity $\mathrm{ML}(1+4) 100^{\circ} \mathrm{C} 33$, was offered by Zhenjiang Nandi Chemical Co., Ltd., China. High-abrasion furnace (CB N110), BET specific surface area $103 \mathrm{~m}^{2} / \mathrm{g}$, 
particle size 10 20 $\mathrm{nm}$ and DBP absorption value of $114 \mathrm{~cm}^{3} / 100 \mathrm{~g}$, was produced from Tianjin Billion Huilong Chemical Technology Co., Ltd., China. BIPB (14S-fl) was purchased from Akzo Nobel Co., Netherlands. Zinc oxide (ZnO), stearic acid (SA), zinc stearate (ZnSA), anti-aging agent poly(1,2-dihydro2,2,4-trimethylquinoline) (RD) were purchased from Tianjin Damao Chemical Reagent Co. Ltd., China.

\subsection{Preparation of $E V M / N B R$ composites}

The preparation process of EVM/NBR composites in the two-step blending method was as follows: (1) As shown in Figure 1, EVM, ingredients $(\mathrm{ZnO} /$ $\mathrm{SA} / \mathrm{ZnSA}), \mathrm{CB}, \mathrm{BIPB}$ or NBR, ingredients $(\mathrm{ZnO} / \mathrm{SA} /$ ZnSA), CB, BIPB were added to the HAAKE Polylab OS torque rheometer in sequence to be plasticized and mixed uniformly according to the formula ratio of Table 1, respectively. The rotor speed of the HAAKE was set to $30 \mathrm{r} / \mathrm{min}$ in $60^{\circ} \mathrm{C}$ and the mixing time of each section was shown in Figure 1. It can obtain EVM compounds A and NBR compounds B with the CB content of $10,20,30,40 \mathrm{phr}$, respectively. (2) The EVM compound A and NBR compound $\mathrm{B}$ with the same $\mathrm{CB}$ content were well mixed together according to the formula ratio in Table 2, for $6 \mathrm{~min}$, in the two-roll mill with the roller distance of $1 \mathrm{~mm}$ at $40^{\circ} \mathrm{C}$. The prepared EVM/NBR compounds were conditioned at $25^{\circ} \mathrm{C}$ for 24 hours. To obtain the sheets of EVM/NBR composites, the EVM/NBR compounds were vulcanized in an electrically heated press at $175^{\circ} \mathrm{C}$ for the optimum cure time $T_{\mathrm{c} 90}$ which was determined by an UCAN UR2030 moving-die rheometer. After that, the cured composites were tested after 24 hours at $25^{\circ} \mathrm{C}$.

\subsection{Characterization}

\subsubsection{Wear and oil resistance measurement}

DIN wear test was recommended by the ISO 4649: 2010 in the wear tester (GT-7012-D, Gotech Testing Machines Inc., Taiwan). A cylindrical sample with a diameter of $16 \mathrm{~mm}$ and a height of $10 \mathrm{~mm}$ was mounted in a rotating holder and abraded across the surface of a rotating abrasive drum for a distance of $40 \mathrm{~m}$. The DIN wear volume $V_{\mathrm{t}}\left[\mathrm{mm}^{3}\right]$ was calculated using Equation (1):

$V_{\mathrm{t}}=\frac{m_{1}-m_{2}}{\rho} \cdot 1000$

where $m_{1}$ and $m_{2}$ are the mass before and after the wear test respectively $[\mathrm{g}], \rho$ is the density $\left[\mathrm{g} / \mathrm{cm}^{3}\right]$.

Table 1. Basic formulas of EVM and NBR rubber.

\begin{tabular}{|c|r|r|r|r|r|r|r|r|r|}
\hline \multirow{2}{*}{ Sample } & EVM & NBR & Carbon black & ZnO & BIPB & RD & \multicolumn{2}{c|}{ SA } & ZnSA \\
\cline { 2 - 10 } & \multicolumn{8}{|c|}{ [phr] (parts per hundred of rubber by weight) } \\
\hline A & 100 & 0 & $10 ; 20 ; 30 ; 40$ & 2.4 & 2.0 & 2.0 & 0.8 & 2.0 \\
\hline B & 0 & 100 & $10 ; 20 ; 30 ; 40$ & 2.4 & 2.0 & 2.0 & 0.8 & 2.0 \\
\hline
\end{tabular}

Table 2. Ratio of EVM/NBR composites by the two-step blending method.

\begin{tabular}{|c|c|c|c|}
\hline Sample codes & Ratio of blending & Sample codes & Ratio of blending \\
\hline EN0 & $\mathrm{A} \times 100 \%+\mathrm{B} \times 0 \%$ & $\mathrm{EN} 40$ & $\mathrm{~A} \times 60 \%+\mathrm{B} \times 40 \%$ \\
\hline $\mathrm{EN} 10$ & $\mathrm{~A} \times 90 \%+\mathrm{B} \times 10 \%$ & $\mathrm{EN} 50$ & $\mathrm{~A} \times 50 \%+\mathrm{B} \times 50 \%$ \\
\hline $\mathrm{EN} 20$ & $\mathrm{~A} \times 80 \%+\mathrm{B} \times 20 \%$ & $\mathrm{EN} 100$ & $\mathrm{~A} \times 0 \%+\mathrm{B} \times 100 \%$ \\
\hline $\mathrm{EN} 30$ & $\mathrm{~A} \times 70 \%+\mathrm{B} \times 30 \%$ & & \\
\hline
\end{tabular}

${ }^{*} \mathrm{~A}$ and B represent the weight of the samples A and B in Table 1 when the carbon black content is 10, 20,30 and 40 phr, respectively.

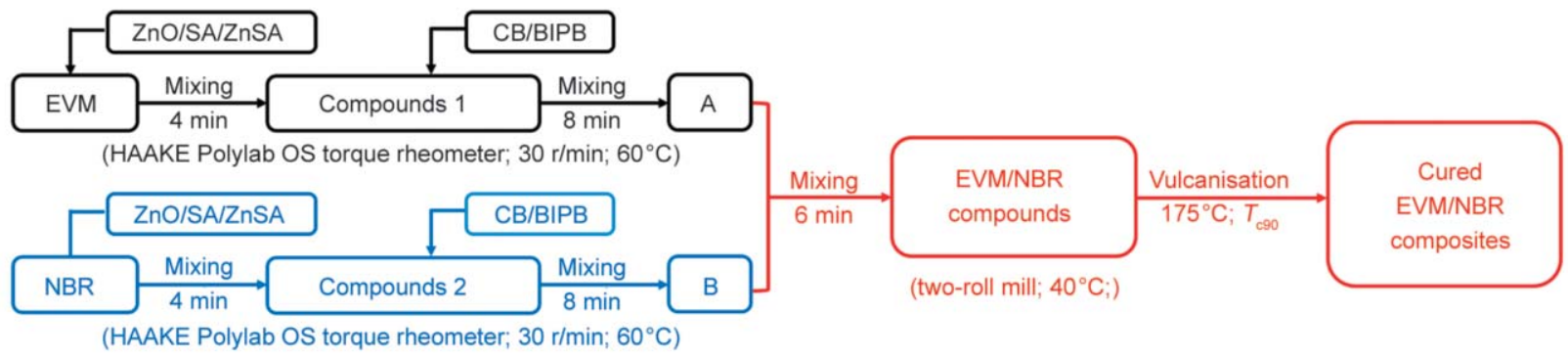

Figure 1. Two-step blending method for preparing EVM/NBR composites. 
The oil resistance test samples that were prepared with a diameter of $16 \mathrm{~mm}$ and thickness of $4 \mathrm{~mm}$ were immersed into 2,2,4-trimethylpentane at $25^{\circ} \mathrm{C}$ for $22 \mathrm{~h}$. The rate of volume and weight change of the samples were determined strictly according to the ISO 1817:2015. The rate of weight change $\Delta m_{100}$ [\%] and volume change $\Delta V_{100}[\%]$ were calculated with Equation (2) and (3) respectively:

$$
\begin{aligned}
& \Delta m_{100}=\frac{m_{\mathrm{i}}-m_{0}}{m_{0}} \cdot 100 \% \\
& \Delta V_{100}=\frac{\rho m_{\mathrm{i}}-\rho_{\mathrm{i}} m_{0}}{\rho_{\mathrm{i}} m_{0}} \cdot 100 \%
\end{aligned}
$$

where $m_{0}[\mathrm{~g}]$ and $m_{\mathrm{i}}[\mathrm{g}]$ are the weight before and after the sample being immersed in liquid, and $\rho_{\mathrm{i}}$ $\left[\mathrm{g} / \mathrm{cm}^{3}\right]$ is the density after the samples being immersed in liquid.

\subsubsection{Morphology and 3D optical profile measurement}

Scanning electron microscope (SEM) observation was performed with an acceleration voltage of $10 \mathrm{kV}$ (Merlin, ZEISS, Germany). The samples were fractured by immersing in liquid nitrogen. The obtained fracture surfaces and the worn surfaces were coated with a thin layer of gold before any observations. Transmission electron microscope (TEM) were observed with an acceleration voltage of $80 \mathrm{kV}$ (JEM2100F, Japan Electronics Corporation, Japan). And the specimens were sliced with a diamond knife with an ultramicrotome. To investigate the worn surfaces roughness of the samples, it were scanned at rang of $0.66 \times 0.88 \mathrm{~mm}$ using 3D optical profiler (Up DualMode, RTEC Instrument Co. Ltd., USA).

\subsubsection{Dynamic mechanical thermal analysis (DMA)}

DMA was measured on a dynamic mechanical thermal analyzer (Q800, TA Instruments, USA). The specimens $(10 \times 6 \times 1 \mathrm{~mm})$ were analyzed in tension mode at a frequency of $1 \mathrm{~Hz}$ with $0.01 \%$ strain, which carried out from -100 to $100^{\circ} \mathrm{C}$ at a heating rate of $3^{\circ} \mathrm{C} / \mathrm{min}$.

\subsubsection{Vulcanization performances measurement} The curing of the composites were determined at $175 \mathrm{C}$ by vulcameter (UR-2030,U-CAN Dynatex Inc., Taiwan). The apparent crosslink density and crosslink density of the composites were estimated by equilibrium swelling experiments. The equilibrium swelling experiments were done at $25^{\circ} \mathrm{C}$ following the recommended procedure published in ref. [8]. Three pieces of each sample $(10 \mathrm{~mm}$ diameter and $2 \mathrm{~mm}$ thickness) were swollen in toluene (molar volume $V_{\mathrm{s}}=106.2 \mathrm{~cm}^{3} / \mathrm{mol}$, density $\left.\rho_{\mathrm{s}}=0.87 \mathrm{~g} / \mathrm{cm}^{3}\right)$. Samples were weighted initially $\left(M_{0}\right)$ with the density $\rho_{\mathrm{r}}\left[\mathrm{g} / \mathrm{cm}^{3}\right]$ and then swollen up to equilibrium during $72 \mathrm{~h}$, renewing the solvent every $24 \mathrm{~h}$. Samples were kept in the dark. In order to determine the mass of swollen samples $(M)[\mathrm{g}]$ every once in a while, we removed the excess of toluene with a tissue and weighted them immediately. Finally, the mass of swollen samples $\left(M_{2}\right)[\mathrm{g}]$ were weighed after $72 \mathrm{~h}$, and the solvent was evaporated from the samples in a vacuum oven for $24 \mathrm{~h}$ at $60^{\circ} \mathrm{C}$ before weighting again the samples $\left(M_{1}\right)$ [g]. Thus, the degree of swelling $Q$ is computed as Equation (4):

$Q=\frac{M-M_{1}}{M_{1}}$

The volume fraction of rubber in swollen gel, which was used to represent the apparent crosslinking density $V_{\mathrm{r}}$ of the vulcanizates, was determined by Equation (5) [23]:

$V_{\mathrm{r}}=\frac{1}{1+\left(\frac{M_{2}}{M_{1}}+1\right) \frac{\rho_{\mathrm{r}}}{\delta \rho_{\mathrm{s}}}}$

$\delta$ is the mass fraction of the polymer in the formula. The crosslink density $V_{\mathrm{e}}$ was estimated from the equilibrium swelling by using the Flory-Rehner equation [24], which is given by Equation (6) [25]:

$V_{\mathrm{e}}=-\frac{\ln \left(1-V_{\mathrm{r}}\right)+V_{\mathrm{r}}+\chi V_{\mathrm{r}}^{2}}{V_{\mathrm{s}}\left(V_{\mathrm{r}}^{1 / 3}-\frac{V_{\mathrm{r}}}{2}\right)}$

It is also important to use a correct value of the FloryHuggins parameter $\chi$, which depends on the volumetric fraction of rubber. For the pair EVM/NBRtoluene, we used 0.444 here [26].

\subsubsection{Physical performances measurement}

A small amount of the uncured EVM/NBR composite with the same shape immersed in toluene for 7 days wrapping in a copper mesh. And the fresh toluene was added to ensure sufficient swelling every 2 days. The swollen sample was dried in a vacuum oven and then weighted again to determine the bound rubber content $W_{\mathrm{R}}$ according to the Equation (7): 
$W_{\mathrm{R}}=\frac{W_{1}-\left(W_{2}-W_{3}\right)}{W_{1}} \cdot 100 \%$

where $W_{1}$ is the mass of EVM/NBR in the EVM/ NBR composite before swelling, $W_{2}$ is the initial mass of EVM/NBR composite, and $W_{3}$ is the mass of EVM/NBR composite after swelling and drying.

The hardness was detected by hardness tester (LX-A, Shanghai Liuling Instrument Co. Ltd., China) according to the ISO 7619:1986. The surface contact angle was measured by droplet imaging analysis system (DSA100 of Kruss, Germany). A small drop of water (ca. $5 \mu \mathrm{L}$ ) was deposited on the surface of the sample, and the pictures were taken over a period of $10 \mathrm{~s}$. The contact angle was calculated by the software.

\section{Results and discussion}

\subsection{Wear resistance of $\mathrm{EVM} / \mathrm{NBR}$ composites}

\subsubsection{DIN abrasion volume}

Wear includes abrasive wear, fatigue wear, adhesion wear and curl wear in rubber [27]. The rubber abrasive wear strength $(I)$ depends on the strength of fracture resistance by applying repeated deformation, being directly proportional to the friction factor $(\mu)$ and pressure $(p)$ and inversely proportional to the tensile strength ( 0$)$ and resilience $(R) . k$ is surface friction constant, following Equation (8) [28]:

$I=k \frac{\mu(1-R)}{\sigma_{0}} p$

Firstly, the effects of NBR and CB bivariate on the DIN abrasion volume of EVM/NBR composites were studied. 3D graph (Figure 2) indicates that the increase of NBR and CB content significantly facilitates the decrease of the abrasion volume of pristine EVM. Meanwhile, the abrasion volume decreases by

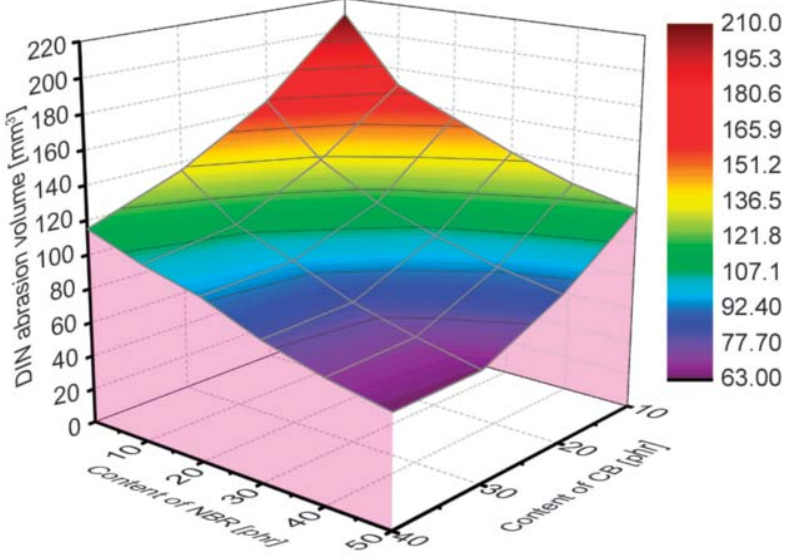

Figure 2. DIN abrasion volume of EVM/NBR composites with different NBR and CB content.
$42.9 \%$ when NBR content increases from 0 to $50 \mathrm{phr}$ in the composites containing $10 \mathrm{phr}$ of CB. By analogy, the abrasion volume decreases by $47.3,52.6$ and $45.2 \%$ when NBR content increases from 0 to $50 \mathrm{phr}$ with $20,30,40 \mathrm{phr}$ of $\mathrm{CB}$, respectively. Therefore, it is the most obvious improvement in wear resistance with $30 \mathrm{phr}$ of CB.

The reason is that the strong polarity of NBR molecule leads to strong intermolecular force. With the increase of NBR content, the cohesive energy density increases rapidly so that it is difficult to rotate within the molecular chain of EVM/NBR composites. Therefore, the stress concentration is weakened and the probability of molecular chain being cut and broken is reduced. When the content of NBR exceeds $30 \mathrm{phr}$, the abrasion volume decreases slowly, probably, due to the transformation of NBR from dispersed phase to a co-continuous phase resulting in the increment of rubber-filler mutual friction. In addition, the content of bound rubber and hardness increase with the increment of $\mathrm{CB}$ content (Figure 5c and 5d) in composites, which make against the improvement of external shear deformation to decrease the abrasion volume [29].

\subsubsection{Worn surfaces morphology}

Figure 3 shows that the worn surfaces appear ridged stripes which are vertical to the sliding direction (Figure 3 red arrow direction) and parallel to each other, the Schallmach pattern, with tiny tongues on the surfaces [16]. As shown in Figure 3a EN0 and $3 b$ EN0, abrasive wear and fatigue wear appear on pristine EVM [18]. Worn surfaces appear the deepest furrow and the uneven ridged stripes with the largest width. There is a lot of wear debris indicating a higher friction coefficient. As shown in Figure 3a EN10, EN30, EN50 or Figure 3b EN10, EN30, EN50, the wear mechanism of EVM/NBR composites is also dominantly abrasive wear. And the SEM images appear even ridged stripes with the narrower width, shallower furrow and the smoother worn surfaces. Moreover, the wear debris effectively decreases with the increment of $\mathrm{CB}$ content on account of lower friction coefficient compared Figure $3 \mathrm{a}$ EN0 and $3 \mathrm{~b}$ EN0, 3a EN10 and 3b EN10, 3a EN30 and 3b EN30, $3 a$ EN50 and $3 b$ EN50 with the CB content of 20 and $30 \mathrm{phr}$. Therefore, the increase of NBR and CB contents within a certain range is beneficial to improve the worn surfaces morphology of EVM/NBR composites. 


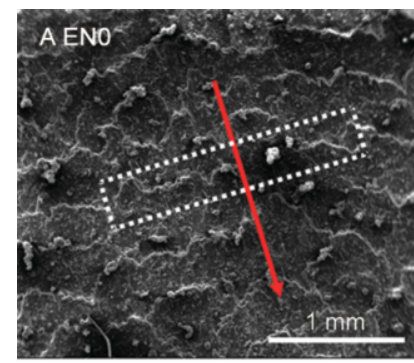

a)

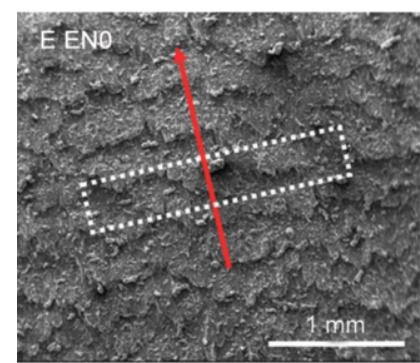

b)
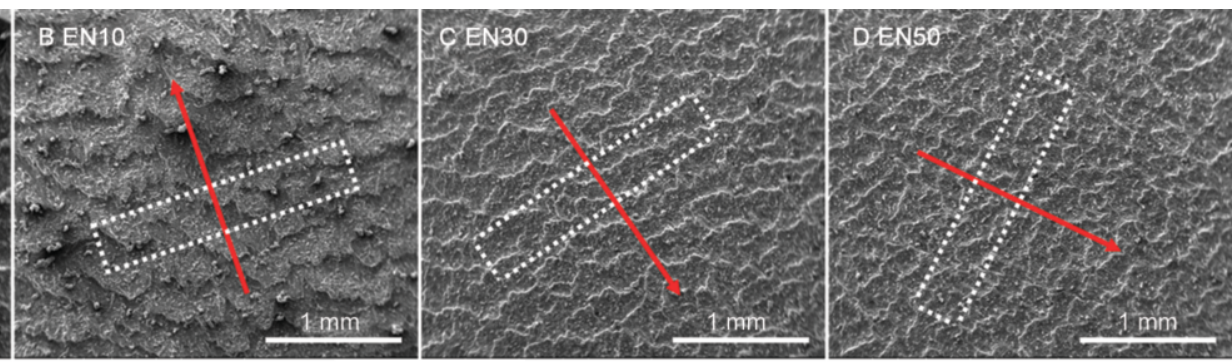

CB $20 \mathrm{phr}$
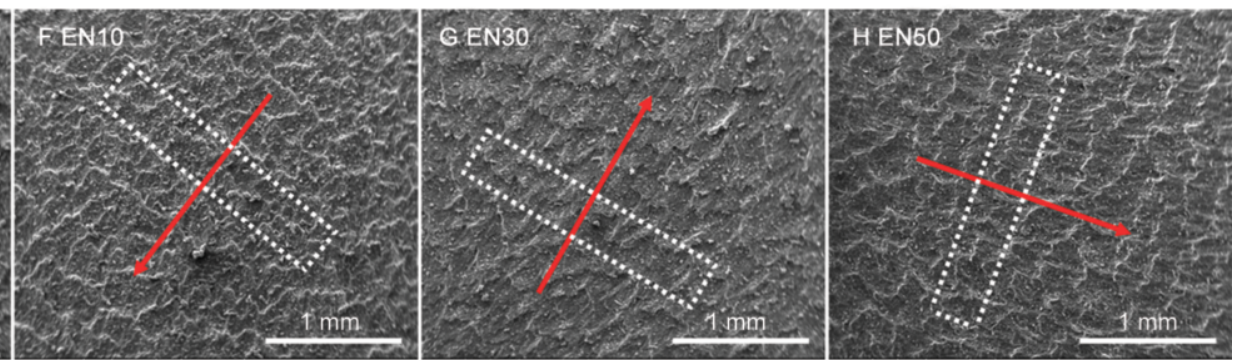

CB $30 \mathrm{phr}$

Figure 3. SEM images of the worn surfaces morphology of EVM/NBR composites with different NBR content, (a) CB $20 \mathrm{phr}$, (b) CB $30 \mathrm{phr}$, the red arrow and white square separately indicates the abrasion sliding direction and paralleled ridged stripes.

Due to the scratch of the sharp micro-protrusion of the rigid surface, local stress concentration is generated on the surface. The composites are subjected to greater friction than its shear strength. It triggers surface crack and periodic tear wear leading to the formation of tongues under the condition of unidirectional relative sliding. Afterwards, the tongues closely turn over after contacting with sharp micro-protrusion again. The crack continues to expand under the repeated pulling force, and the tensile stress causes the root of the tongues to break resulting in wear debris. Hence, the stripe pattern, Schallmach pattern, slowly moves to the sliding direction to form the ridged stripes during the wear process.

\subsubsection{Worn surfaces 3D optical profile}

The 3D optical profile, surface roughness $\left(R_{\mathrm{a}}\right)$, root mean square roughness $\left(R_{\mathrm{ms}}\right)$ of the worn surfaces are measured as shown in Figure 4 and Table 3. Generally, the smaller surface roughness is, the smoother surface is, which means that the composites exhibit

Table 3. Worn surfaces roughness of EVM/NBR composites with different NBR content.

\begin{tabular}{|c|ll|r|r|r|r|r|c|}
\hline \multirow{2}{*}{$\begin{array}{c}\text { CB } \\
\text { [phr] }\end{array}$} & \multirow{2}{*}{ Roughness } & \multicolumn{6}{|c|}{ Sample codes } \\
\cline { 3 - 9 } & & EN0 & EN10 & EN20 & EN30 & EN40 & EN50 \\
\hline \multirow{2}{*}{20} & $R_{\mathrm{a}}$ & {$[\mu \mathrm{m}]$} & 13.5 & 10.3 & 9.5 & 8.1 & 7.8 & 7.0 \\
\cline { 2 - 8 } & $R_{\mathrm{ms}}$ & {$[\mu \mathrm{m}]$} & 16.3 & 12.3 & 11.3 & 10.1 & 9.5 & 8.5 \\
\hline \multirow{2}{*}{30} & $R_{\mathrm{a}}$ & {$[\mu \mathrm{m}]$} & 12.2 & 9.2 & 8.1 & 7.3 & 6.8 & 5.6 \\
\cline { 2 - 8 } & $R_{\mathrm{ms}}$ & {$[\mu \mathrm{m}]$} & 15.0 & 11.2 & 10.0 & 9.2 & 8.5 & 7.1 \\
\hline
\end{tabular}

a smaller friction coefficient and have better wear resistance to shear deformation. As shown in Figure 4a EN0 and $4 \mathrm{~b}$ EN0, the 3D optical profile grooves are wide and deep of pristine EVM. The $R_{\mathrm{a}}$ are 13.5 and $12.2 \mu \mathrm{m}$, and $R_{\mathrm{ms}}$ are 16.3 and $15.0 \mu \mathrm{m}$ with the CB content of 20 and $30 \mathrm{phr}$, respectively. When NBR reaches $50 \mathrm{phr}$, the $3 \mathrm{D}$ optical profile grooves become narrower and shallower as shown in Figure 4a EN50 and $4 \mathrm{~b}$ EN50, and $R_{\mathrm{a}}$ decreases by $48 \%$ and $54 \%$ with the CB content of 20 and 30 phr. These results indicate the improvement of wear resistance as revealed by the result of the SEM.

\subsection{Oil resistance of $E V M / N B R$ composites \\ 3.2.1. Rate of volume and weight change}

Determination of the rate of volume and weight change of rubber after immersion in the medium plays an important role in predicting the oil resistance of rubber [30]. Figure $5 \mathrm{a}$ and $5 \mathrm{~b}$ show the 3D graphs that the rate of volume and weight change of the composites decrease by 38.0 and $48.0 \%$ when NBR content increases from 0 to $50 \mathrm{phr}$ in the composites containing $10 \mathrm{phr}$ of $\mathrm{CB}$. By analogy, the rate of volume change decreases by $58.8,59.0$ and $56.1 \%$ and the rate of weight change rate decreases by 57.2 , 56.1 and $55.3 \%$ when NBR content increases from 0 to $50 \mathrm{phr}$ with 20,30 and $40 \mathrm{phr}$ of $\mathrm{CB}$, respectively. Therefore, the oil resistance is greatly reduced with 30 phr of CB. 

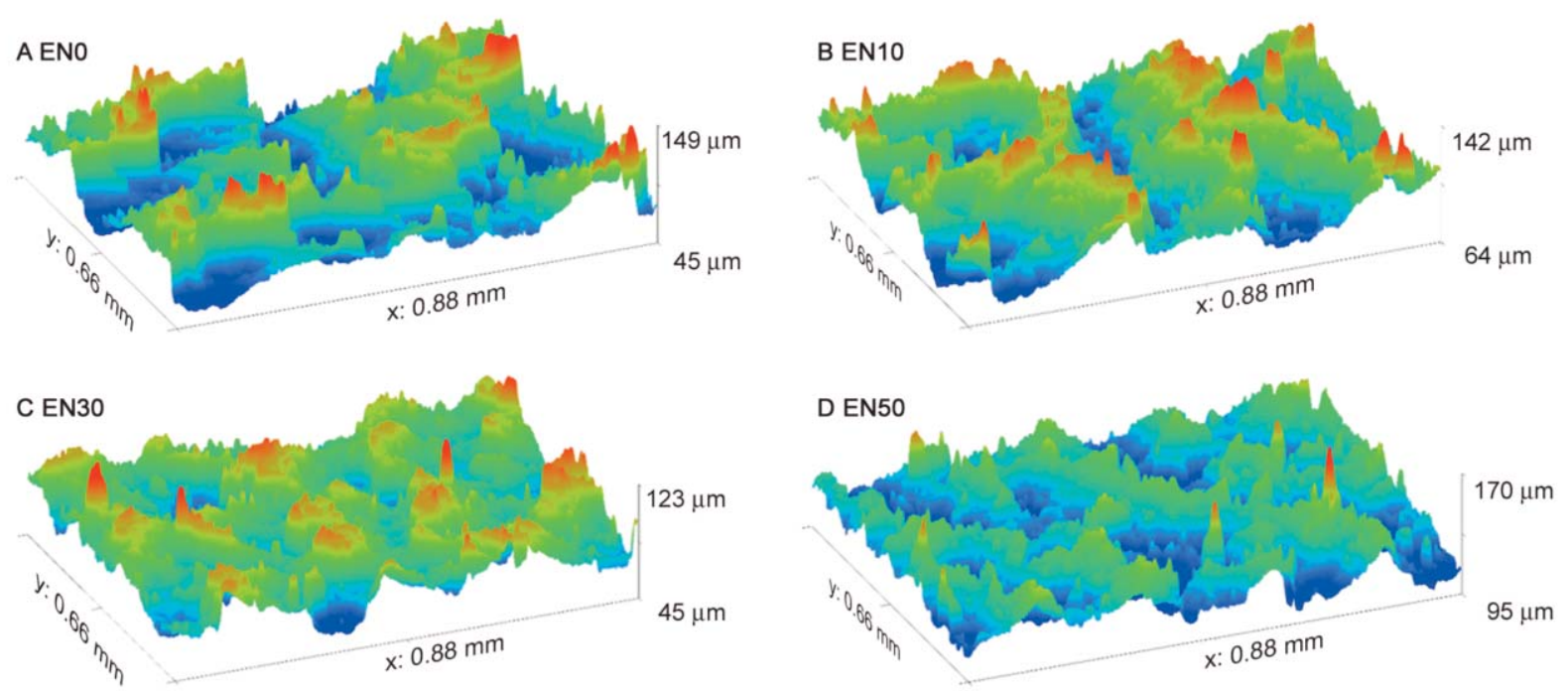

a)

CB $20 \mathrm{phr}$
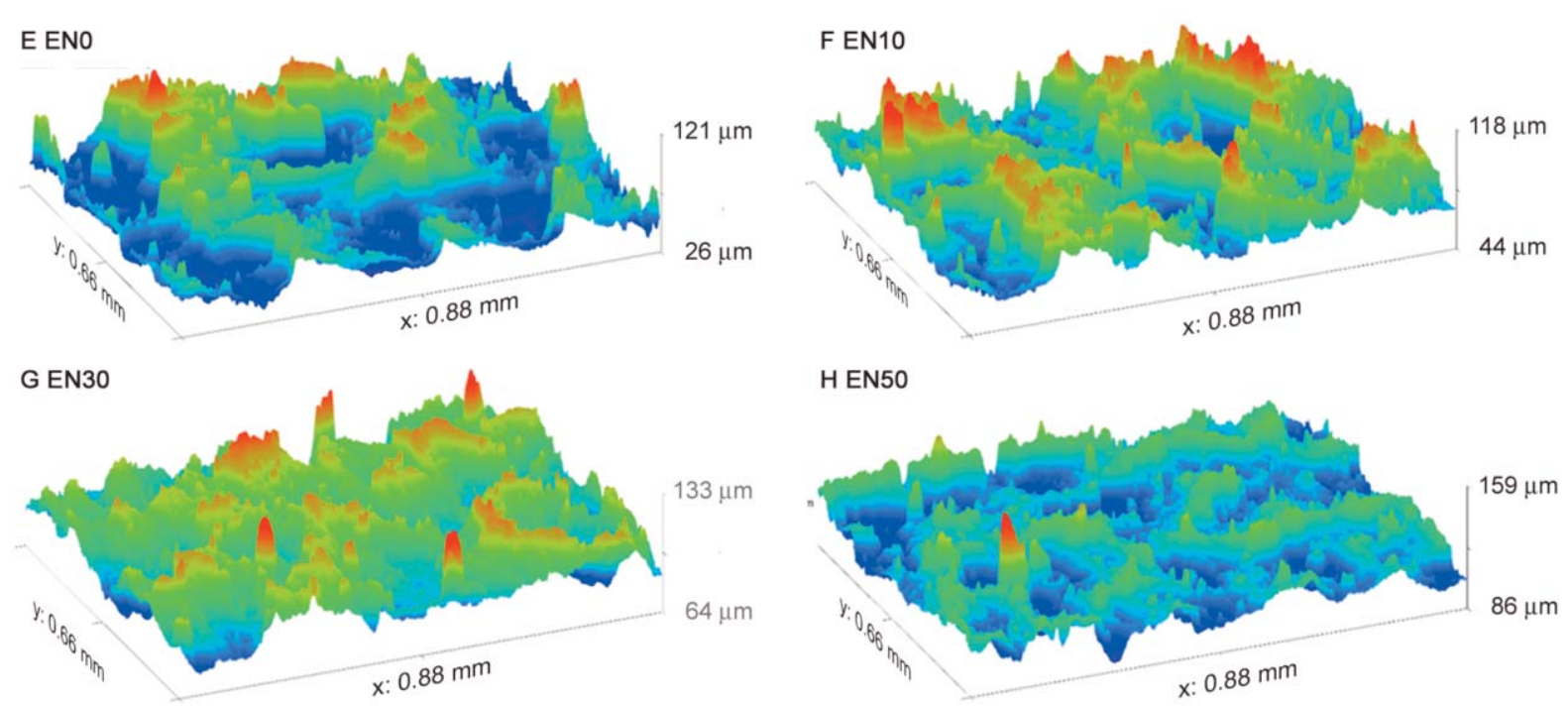

b)

CB $30 \mathrm{phr}$

Figure 4. Worn surfaces 3D optical profile of EVM/NBR composites with different NBR content, (a) CB 20 phr, (b) CB $30 \mathrm{phr}$.

The increment of NBR content plays a excellent effect on the oil resistance of the composites. The schematic diagram of oil molecule impregnation resistance of the composites is shown in Figure 6. There is an excellent compatibility between the weakly polarity EVM and non-polarity oil molecules. The oil molecules enormously enter the matrix directly per unit time, so the swelling volume changes greatly. While the NBR chain contains a strong polarity cyano group, which extremely excludes to the nonpolarity oil molecules and availably prevents oil molecules entering the matrix directly. So the oil molecules entering the matrix are limited and the swelling volume rarely changes [31].
It is worth noting that the rate of volume and weight change of the composites decrease when the CB content varies from 10 to $30 \mathrm{phr}$, but that are slightly raised in more than $30 \mathrm{phr}$ of $\mathrm{CB}$. This is ascribed to that the increase of $\mathrm{CB}$ content promotes the increment of physical and chemical entanglement, which leads to the significantly increase of the bound rubber content and hardness (Figure $5 \mathrm{c}$ and $5 \mathrm{~d}$ ) of the composites. Meanwhile, CB is more difficult to be swollen than the polymer chains. When the content of $\mathrm{CB}$ exceeds $30 \mathrm{phr}$, in spite of appearing the growth of hardness, the agglomeration of the $\mathrm{CB}$ is easily generated in the polymer matrix. So the effective contact area between the CB and the matrix is reduced 

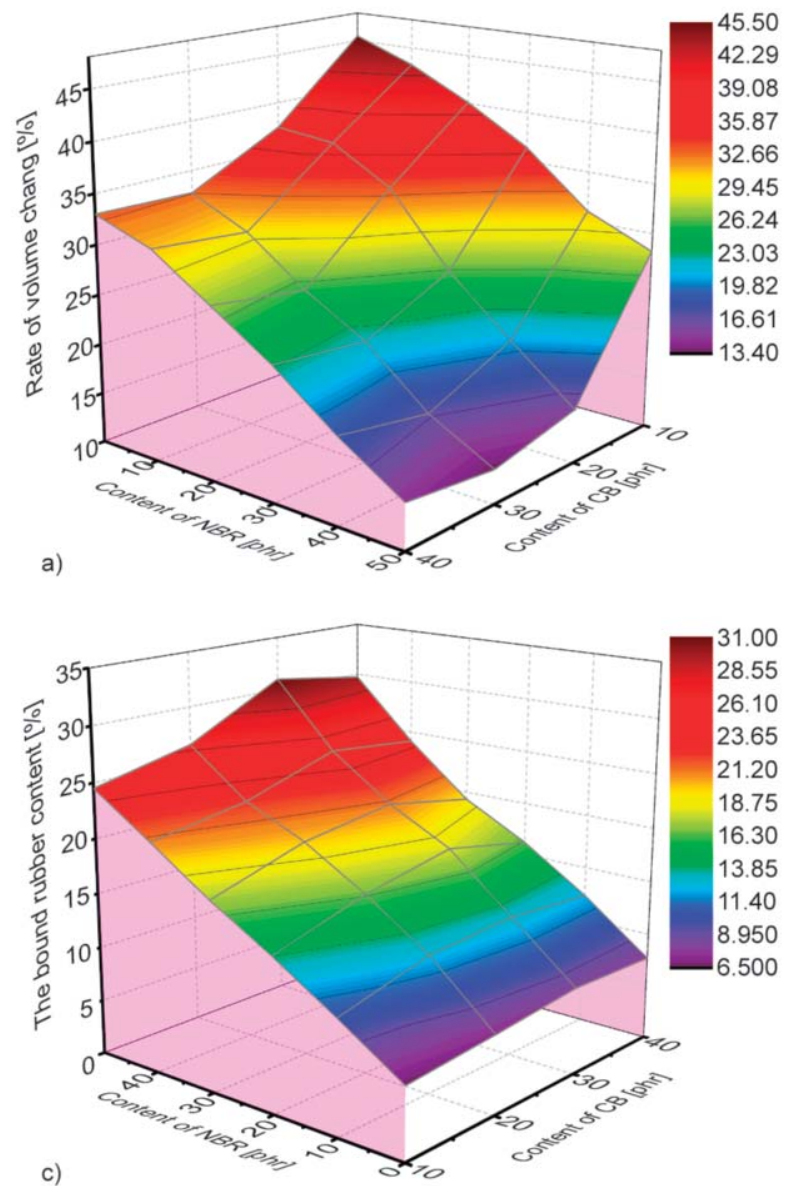
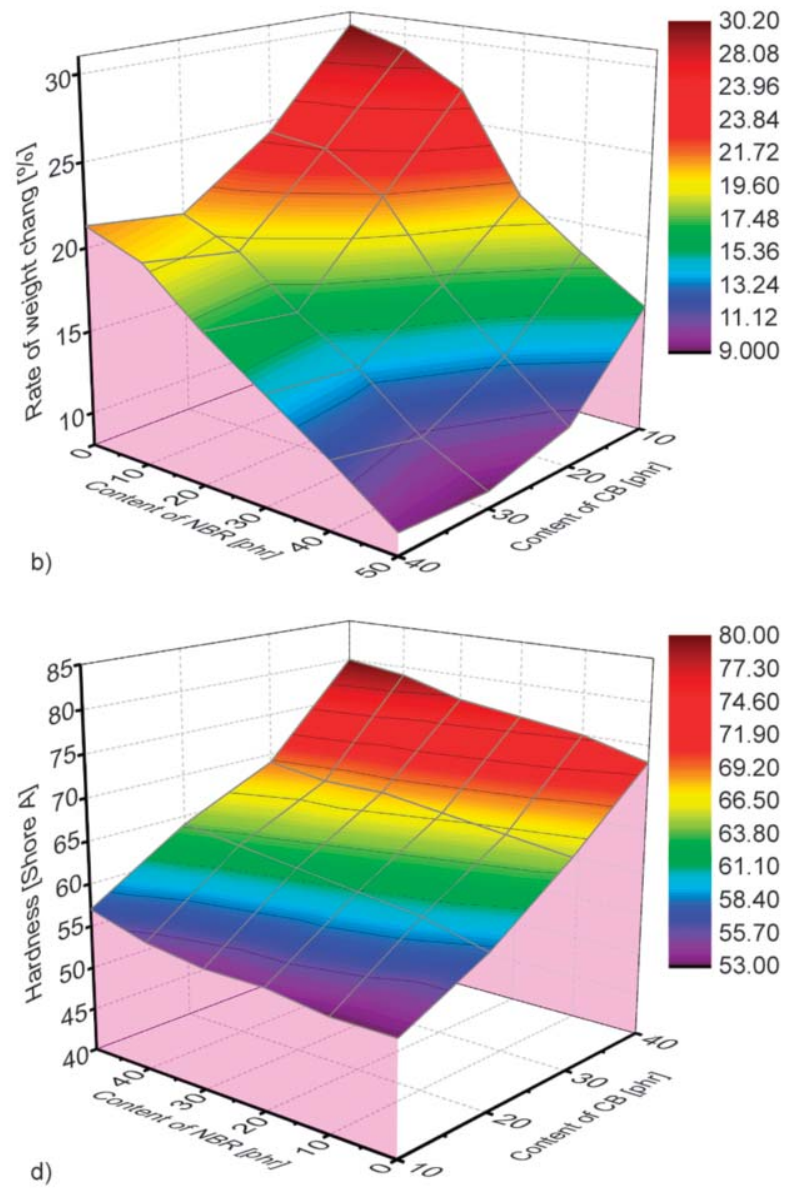

Figure 5. (a) Oil resistance rate of volume change (b) rate of weight change (c) the bound rubber content and (d) hardness of EVM/NBR composites with different NBR and CB content.

leading to the drop of the bound rubber (Figure $5 \mathrm{c}$ ), which in turn reduces the oil resistance [32]. Figure $5 \mathrm{~d}$ shows that the addition of $\mathrm{CB}$ greatly improves the hardness of the composites, and the addition of NBR has a moderate increase on the hardness. This may be ascribed to that the increase of CB content significantly promotes the increment of physical and chemical cross-linking compared with NBR. The hardness maintains about 65 degrees of Shore A in the composites containing $30 \mathrm{phr}$ of $\mathrm{CB}$, which plays an important role in obtaining a soft polymer composite.

\subsubsection{Surface contact angle}

The oleophobicity of the material can be explained from the contact angle $\theta_{\mathrm{e}}$ that is a measure of the material wetting. The smaller $\theta_{\mathrm{e}}$ is, the more oleophobic material surface is. It can be seen from Figure 7, for pristine EVM, $\theta_{\mathrm{e}}$ is 116.8 and $113.6^{\circ}$ in samples containing 20 and $30 \mathrm{phr}$ of $\mathrm{CB}$, respectively, and the surface of the material behaves as lipophilic. $\theta_{\mathrm{e}}$ decreases by 34.2 and $38.3 \%$ behaving as hydrophilic, when NBR reaches $50 \mathrm{phr}$ in samples containing 20 and $30 \mathrm{phr}$ of $\mathrm{CB}$, respectively. The surface of the $\mathrm{CB}$ contains polar groups including hydroxyl group, carboxyl group, and carbonyl group. NBR has cyano group, which are all polar groups. Therefore, the polarity of the sample surface was enhanced, leading to better hydrophilism and enhanced ability to resist swelling in oil as revealed by the result of the oil resistance testing.

Table 4 compares the properties of EVM/NBR composites prepared by the direct and two-step blending. The abrasion volume, oil resistance rate of volume and weight change decrease by 30.0, 25.1 and $24.5 \%$ by the two step blending method. And the bound rubber content increases by $28.6 \%$. This may be ascribed to that the ingredients and $\mathrm{CB}$ can disperse well, which effectively weakens the difficulty of dispersion due to polarity difference between the filler and polymers by the two-step blending method. 


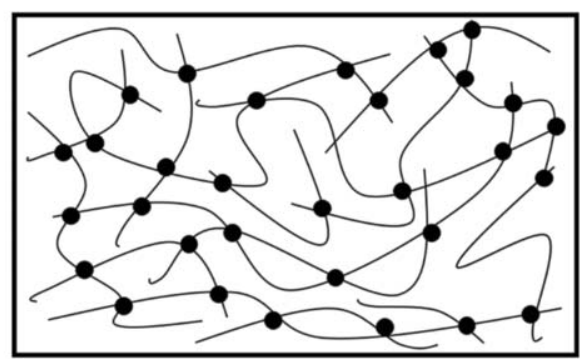

Pure EVM system

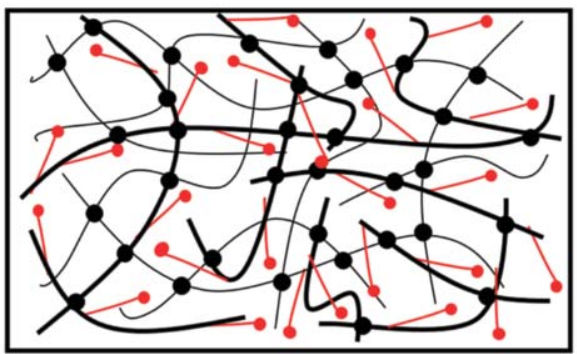

EVM/NBR system

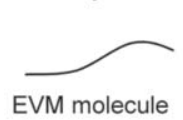

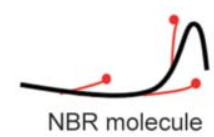

Swelling

$22 \mathrm{~h}, 25^{\circ} \mathrm{C}$

Swelling

$22 \mathrm{~h}, 25^{\circ} \mathrm{C}$
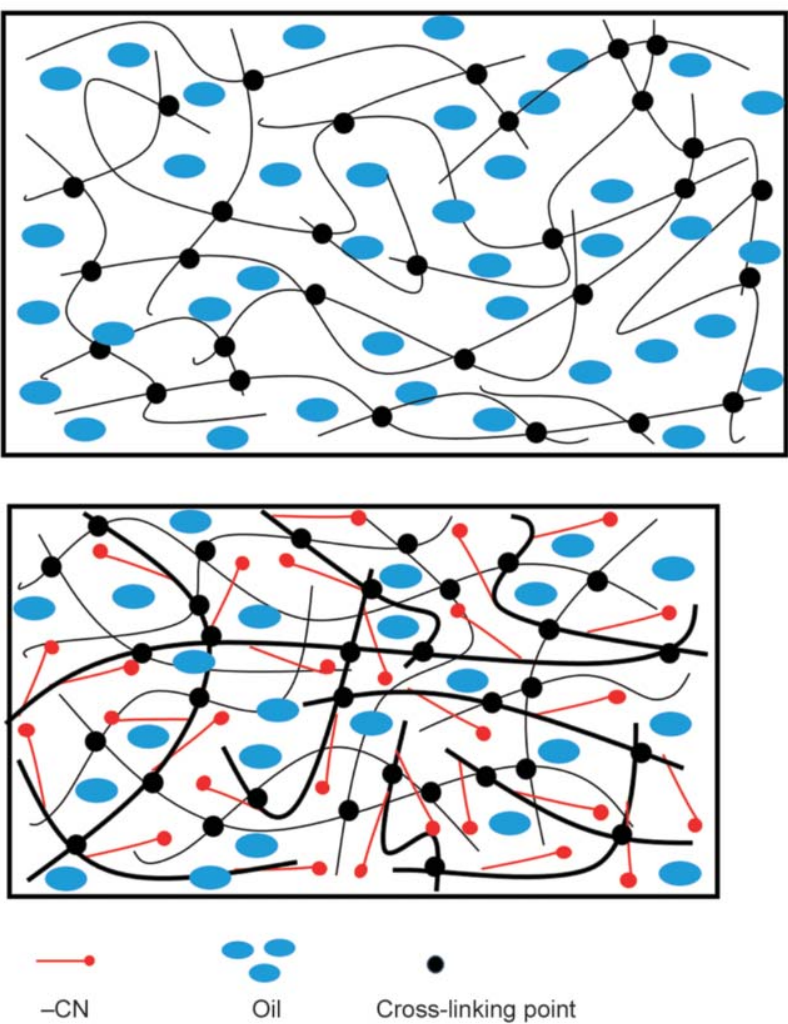

Figure 6. Schematic diagram of oil molecule impregnation resistance of pristine EVM and EVM/NBR composites.

Table 4. Comparison of properties of EVM/NBR composites prepared by the direct and two-step blending methods (NBR $30 \mathrm{phr}, \mathrm{CB} 30 \mathrm{phr})$.

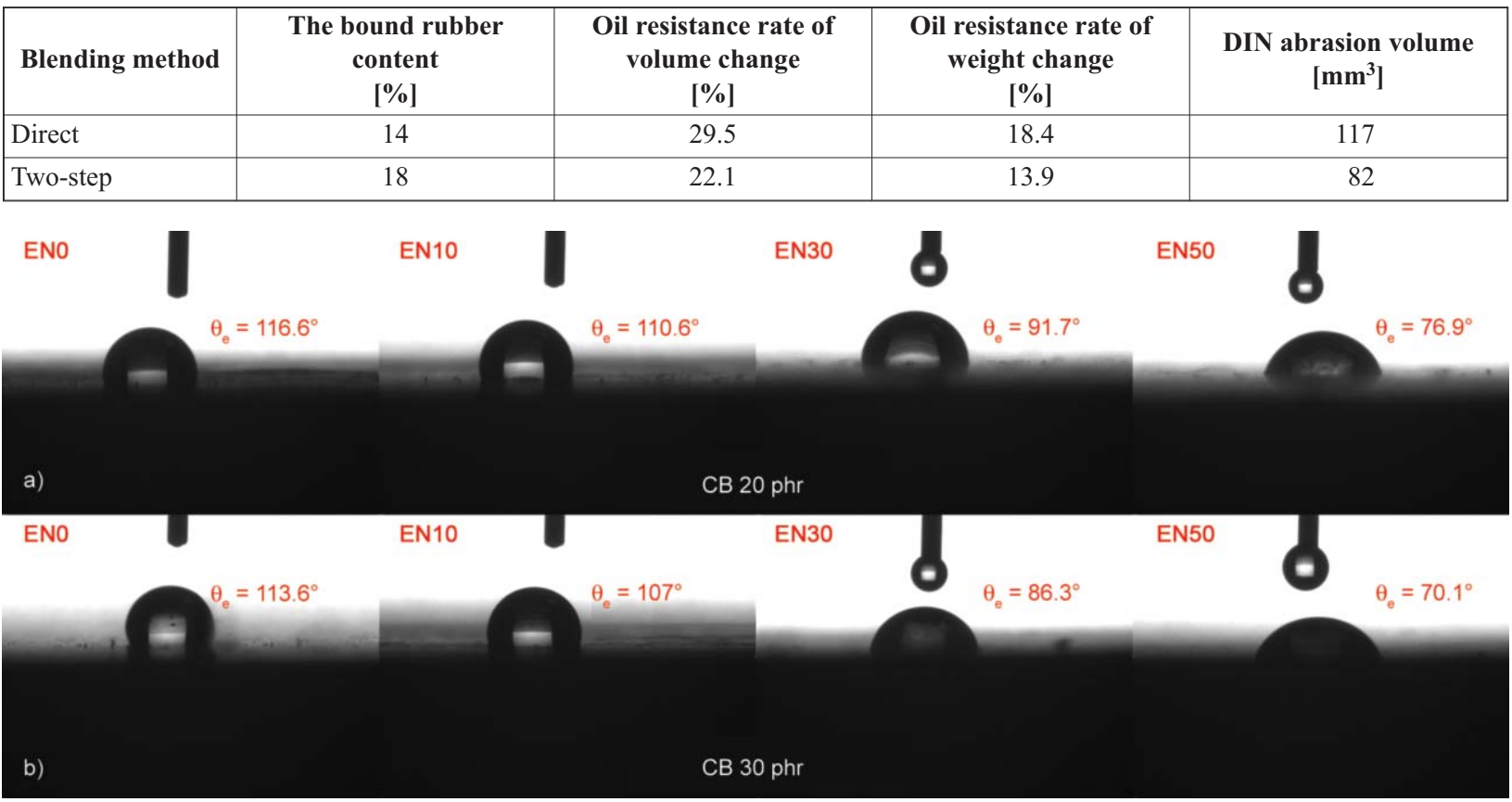

Figure 7. Surface contact angle of EVM/NBR composites with different NBR content. (a) CB 20 phr, (b) CB 30 phr.

\subsection{Vulcanization performances of EVM/NBR composites}

The EVM/NBR composites exhibited excellent wear and oil resistance containing $30 \mathrm{phr}$ of $\mathrm{CB}$, so $30 \mathrm{phr}$ of $\mathrm{CB}$ was selected for the following filler content.
As shown in Figure 8a and Table 5, the $\Delta H\left(M_{\mathrm{H}^{-}}-M_{\mathrm{L}}\right)$ increases with the increment of the NBR content and the EVM/NBR composites shows higher $\Delta H$ than pristine EVM or NBR does. This indicates that chemical cross-linking has also occurred between the 


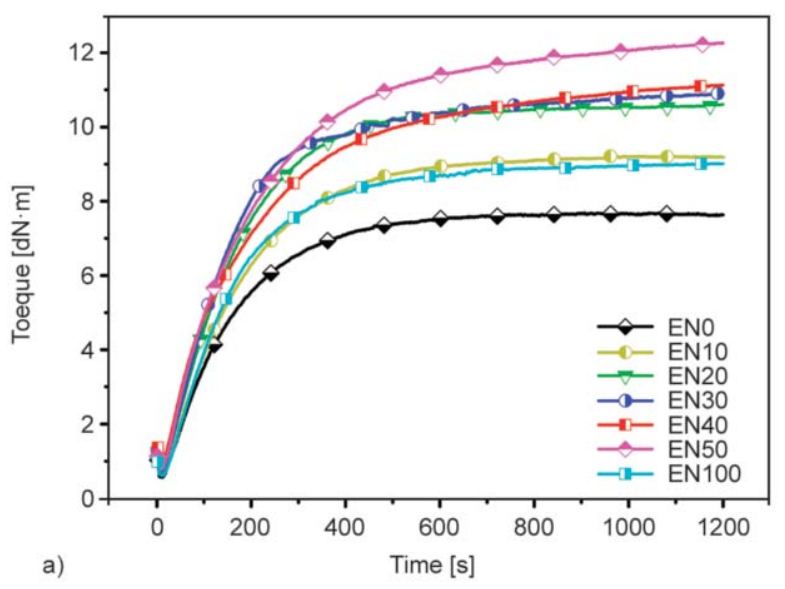

Figure 8. Effects of NBR content on (a) vulcanization curves

EVM and NBR by the two-step blending method. $\Delta H$ increases by $61.2 \%$ when the NBR content varies from 0 to $50 \mathrm{phr}$. One reason is the strong intermolecular force of the NBR and the other is that the crosslink density is gradually increased [33]. As shown in Figure $9 \mathrm{~b}$, the $V_{\mathrm{r}}$ and the $V_{\mathrm{e}}$ increase by 1.9 times and 4.8 times, respectively, when the NBR content increases from 0 to $50 \mathrm{phr}$.

It is obvious that the vulcanization rate of pristine NBR is greater than EVM (Figure 8b). It also can be assumed that the crosslinking of NBR may be prior to the EVM in the composites. This is owing to the fact that BIPB radicals promote NBR active free radical more than EVM during vulcanization totally because of active double bonds of NBR. Figure $8 b$ shows that the vulcanization rate of composites is greater than that of pristine NBR or EVM around the maximum cure rate peak. This is ascribed to that some co-crosslinking may be generate between NBR and EVM molecular chain as shown in Figure 10 [35]. Table 5 shows that the positive cure time $T_{\mathrm{c} 90}$ has some elongation than that of pristine EVM. This

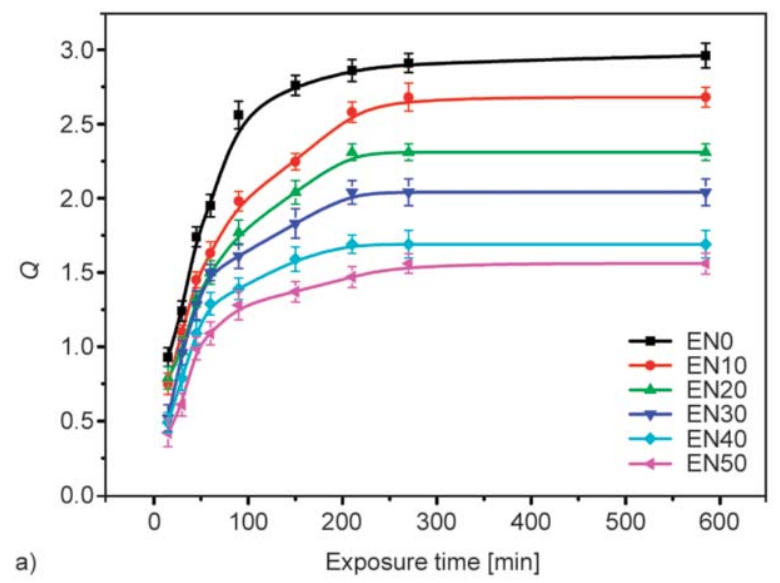

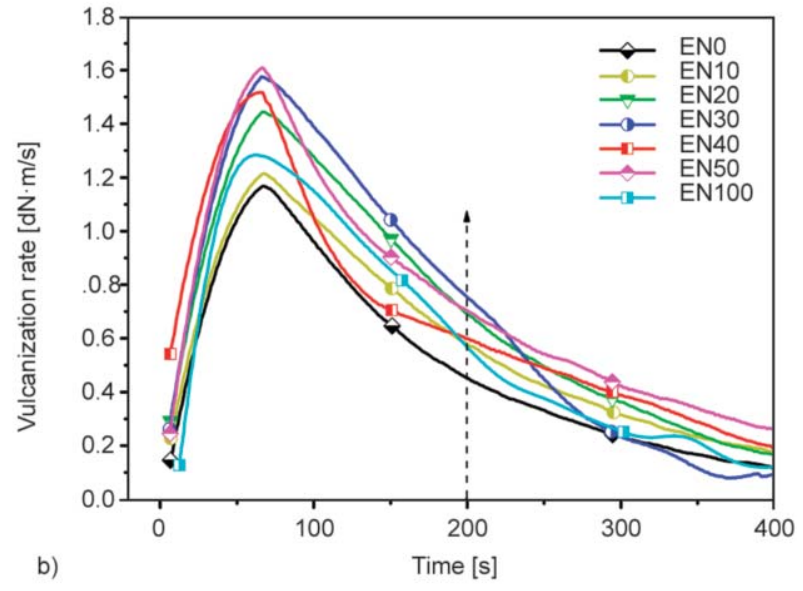

(b) vulcanization rate curves of EVM/NBR composites.

may be due to the existence of co-crosslinking of the composites. The scorch time $T_{\mathrm{s} 2}$ decreases than that of pristine EVM and NBR. This may be due to that the two-step blending method and the increment of polarity all promote the dispersion of the crosslinking ingredients in the matrix, which promotes the crosslinking speed.

As shown in Figure 10, the symbol $\mathrm{R}_{1} \bullet$ and $\mathrm{R}_{2} \bullet$ represent the free radicals generated by BIPB at high temperature, which respectively capture the $\mathrm{H}$ atom of the EVM and NBR molecular chains, inducing the EVM and NBR molecular free radicals. By the two-step blending method, firstly, the molecular free radicals crosslink intramolecularly forming a small cross-linking network with free radicals, and then each small cross-linking network co-crosslinks through free radical pairing leading to the increment of the $\Delta H$. Moreover, the NBR molecular chain contains unstable double bonds with high reaction reactivity, so the pristine NBR has a higher vulcanization rate than EVM (Figure 8b). It is also produced more chemical cross-linking points in NBR molecular

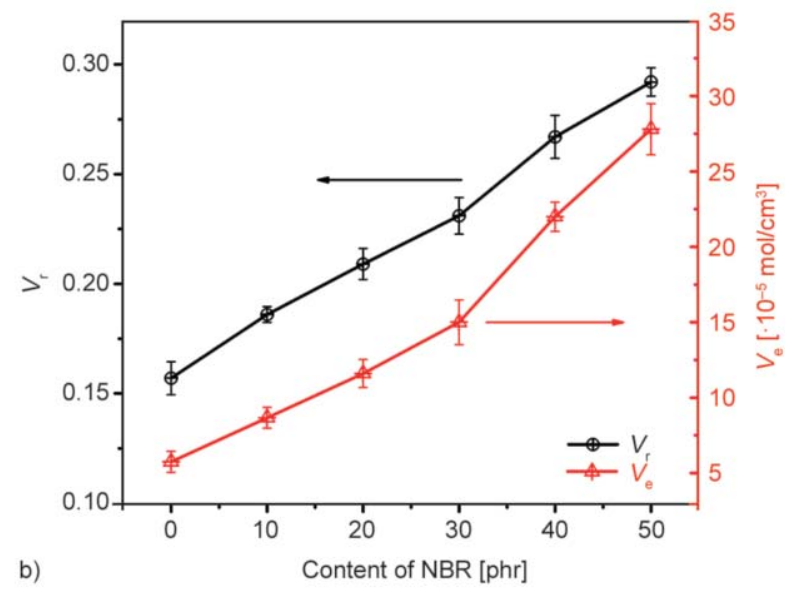

b)

Figure 9. Effects of NBR content on (a) equilibrium swelling (b) $V_{\mathrm{r}}$ and $V_{\mathrm{e}}$ of EVM/NBR composites. 


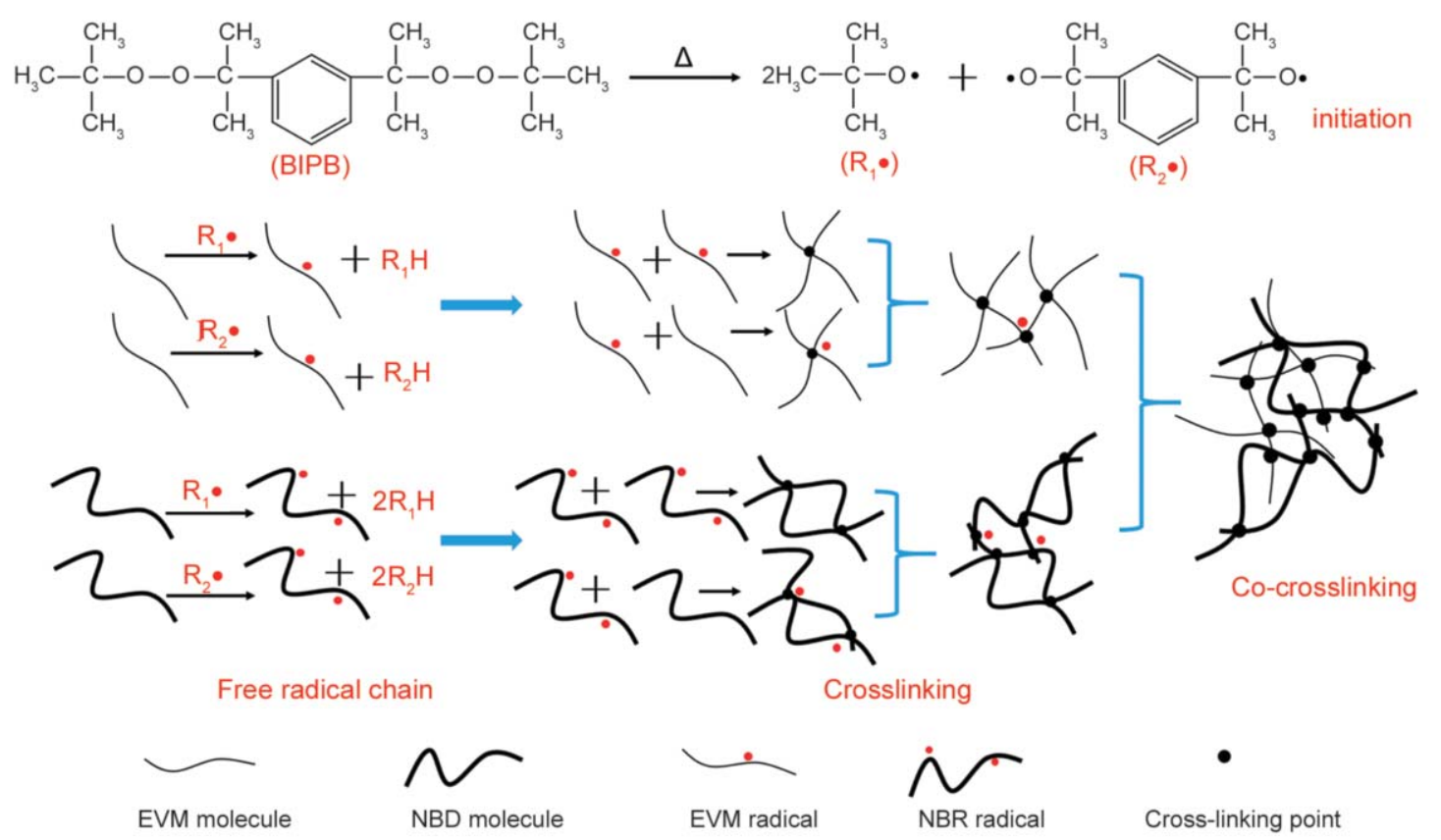

Figure 10. Schematic diagram of BIPB vulcanized EVM/NBR composites by the two-step blending.

Table 5. Vulcanization datas of EVM/NBR composites with different NBR content.

\begin{tabular}{|l|c|c|c|c|c|}
\hline $\begin{array}{c}\text { Sample } \\
\text { codes }\end{array}$ & $\begin{array}{c}\boldsymbol{T}_{\mathbf{s 2}} \\
{[\mathbf{m i n}]}\end{array}$ & $\begin{array}{c}\boldsymbol{T}_{\mathbf{c 9 0}} \\
{[\mathbf{m i n}]}\end{array}$ & $\begin{array}{c}\boldsymbol{M}_{\mathbf{L}} \\
{[\mathbf{d N} \cdot \mathbf{m}]}\end{array}$ & $\begin{array}{c}\boldsymbol{M}_{\mathbf{H}} \\
{[\mathbf{d N} \cdot \mathbf{m}]}\end{array}$ & $\begin{array}{c}\Delta \boldsymbol{M} \\
{[\mathbf{d N} \cdot \mathbf{m}]}\end{array}$ \\
\hline EN0 & 1.15 & 6.18 & 0.57 & 7.69 & 7.12 \\
\hline EN10 & 1.12 & 6.87 & 0.69 & 9.22 & 8.53 \\
\hline EN20 & 0.98 & 6.10 & 0.78 & 10.61 & 9.83 \\
\hline EN30 & 0.92 & 6.95 & 0.69 & 10.90 & 10.21 \\
\hline EN40 & 0.85 & 9.08 & 0.91 & 11.13 & 10.22 \\
\hline EN50 & 0.85 & 8.58 & 0.79 & 12.27 & 11.48 \\
\hline EN100 & 1.12 & 6.40 & 0.60 & 9.02 & 8.42 \\
\hline
\end{tabular}

${ }^{*} \Delta M$ : difference between maximum torque $\left(M_{\mathrm{H}}\right)$ and minimum torque $\left(M_{\mathrm{L}}\right) ; T_{\mathrm{s} 2}$ : scorch time.

chain per unit volume than the EVM [34]. That all explains the increment of crosslink density.

Figure 9a also shows that NBR can significantly reduces the swelling of vulcanized rubber. On the one hand, NBR are more resistant to the swelling of toluene. On the other hand, the $V_{\mathrm{r}}$ and $V_{\mathrm{e}}$ increase with the rise of NBR content (Figure $9 b$ ), forming a tighter cross-linked network to restrict the molecular segment mobility. So the cross-linked segment is more difficult to stretch and is also not easily swelled by 2,2,4-trimethylpentane.

\subsection{Micro-morphology of EVM/NBR composites}

Figure 11 shows the low temperature brittle fracture surfaces for EVM/NBR composites. It can be seen that the filler particles are mostly exposed outside for pristine EVM, which is weakly connected with the matrix, showing a tiny fish scale pattern (Figure 11a). As shown in Figure 11c and 11e, the exposed filler particles are tightly coated by rubber molecular chain as the increase of NBR content. There is also no obvious phenomenon of agglomeration to significantly improve the interface between the filler and resin in the composites.

The microstructure of the composites is further verified by TEM, as shown in Figure 12. It shows that there are multiple clusters of filler in pristine EVM and the agglomerates are larger, but the filler are more evenly dispersed than pristine EVM in EVM/NBR composites only occurring a slight small agglomeration (Figure 12c and 12e). According to the principle of equal viscosity of the blending, it is easy to obtain a uniformly dispersed blends if the two polymers are similar to the viscosity. But the EVM and NBR are different in mooney viscosity. It can effectively weaken the difficulty of dispersion due to interaction difference between the filler and the polymers by the two-step blending method, instead of mixing the filler and EVM/NBR together. Figure $12 \mathrm{~b}, 12 \mathrm{~d}$ and $12 \mathrm{f}$ are the enlarged pictures of Figure $12 \mathrm{a}, 12 \mathrm{c}$, and $12 \mathrm{e}$, respectively. It also can be found that the dispersion of the filler is much more uniform with the increase of NBR content, which enhances the interaction between filler and resin. This reduces the probability of filler frictional shedding and increases the content of bound rubber (Figure $5 \mathrm{c}$ ). 

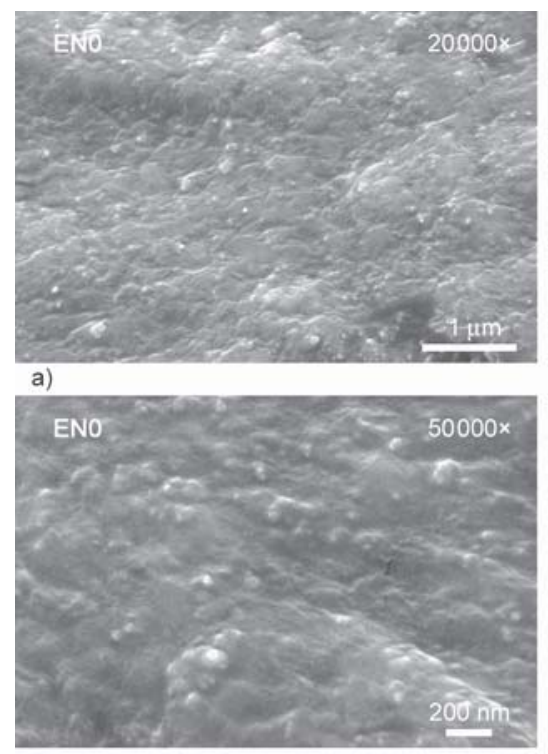

b)
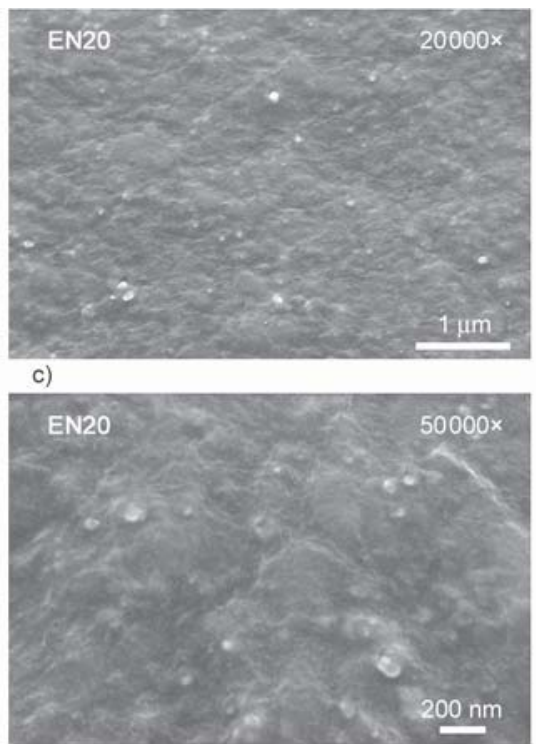

d)

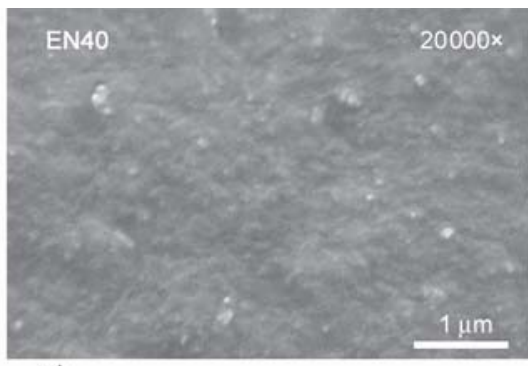

e)

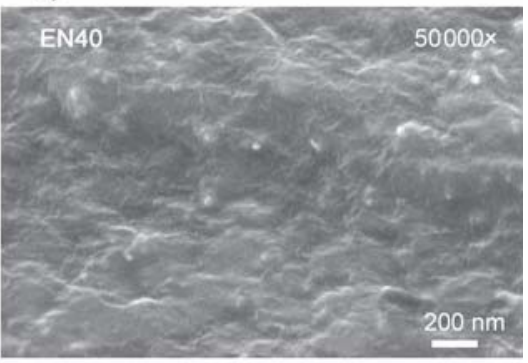

f)

Figure 11. SEM images of EVM/NBR composites with different NBR content. a) and b) 0 phr NBR, c) and d) 20 phr NBR, e) and f) $40 \mathrm{phr}$ NBR with $30 \mathrm{phr}$ of CB.

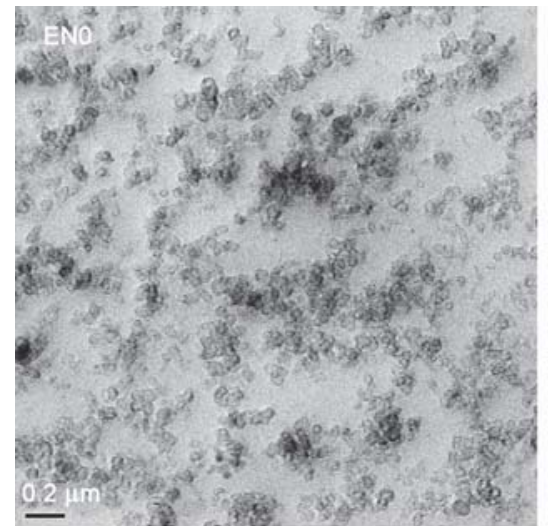

a)

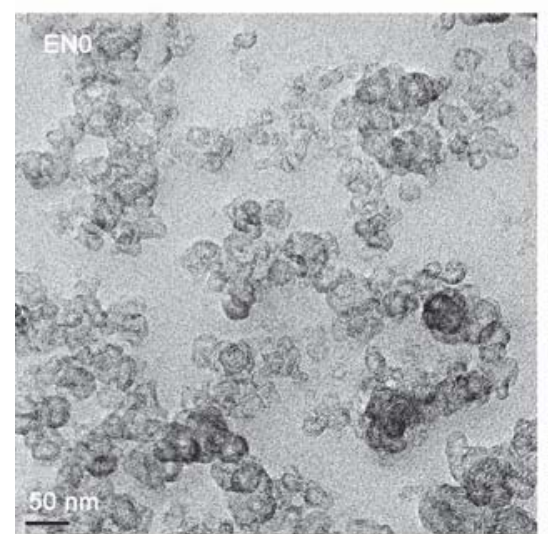

b)

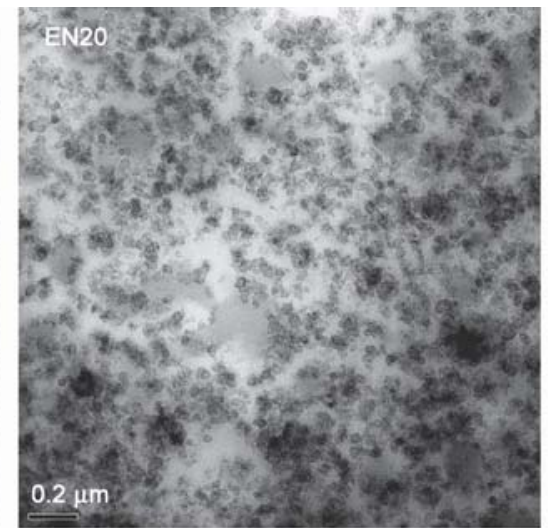

c)

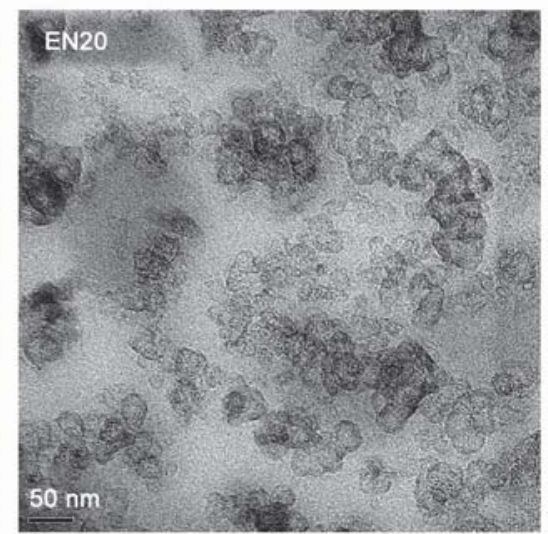

d)

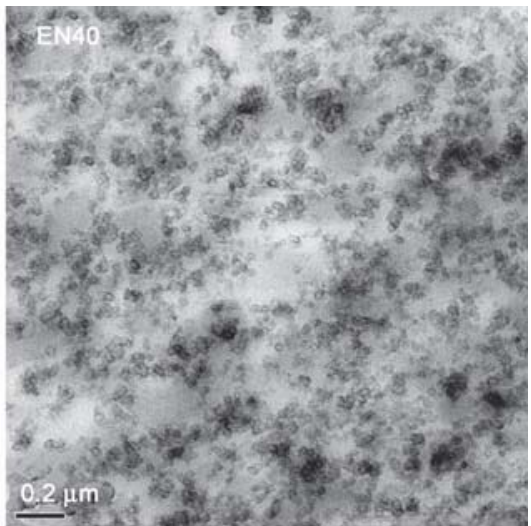

e)

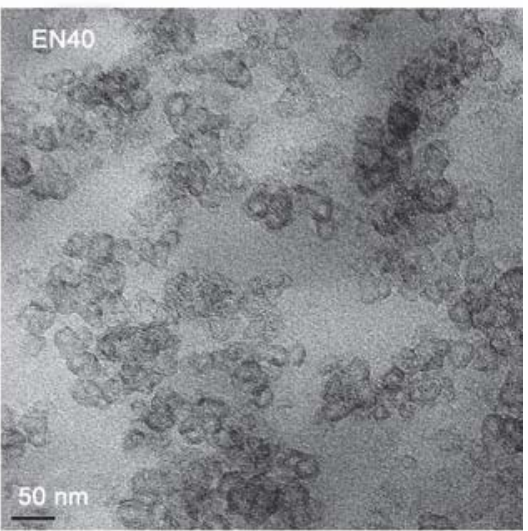

f)

Figure 12. TEM images of EVM/NBR composites with different NBR content. a) and b) 0 phr NBR, c) and d) 20 phr NBR, e) and f) $40 \mathrm{phr}$ NBR with $30 \mathrm{phr}$ of CB.

So the increase of polarity and the improvement of processing method contribute to the improvement of the wear and oil resistance of the composites.

\subsection{Dynamic mechanical thermal analysis of EVM/NBR composites}

Figure 13 shows temperature dependence of the storage modulus $E^{\prime}$ of the composites with different 

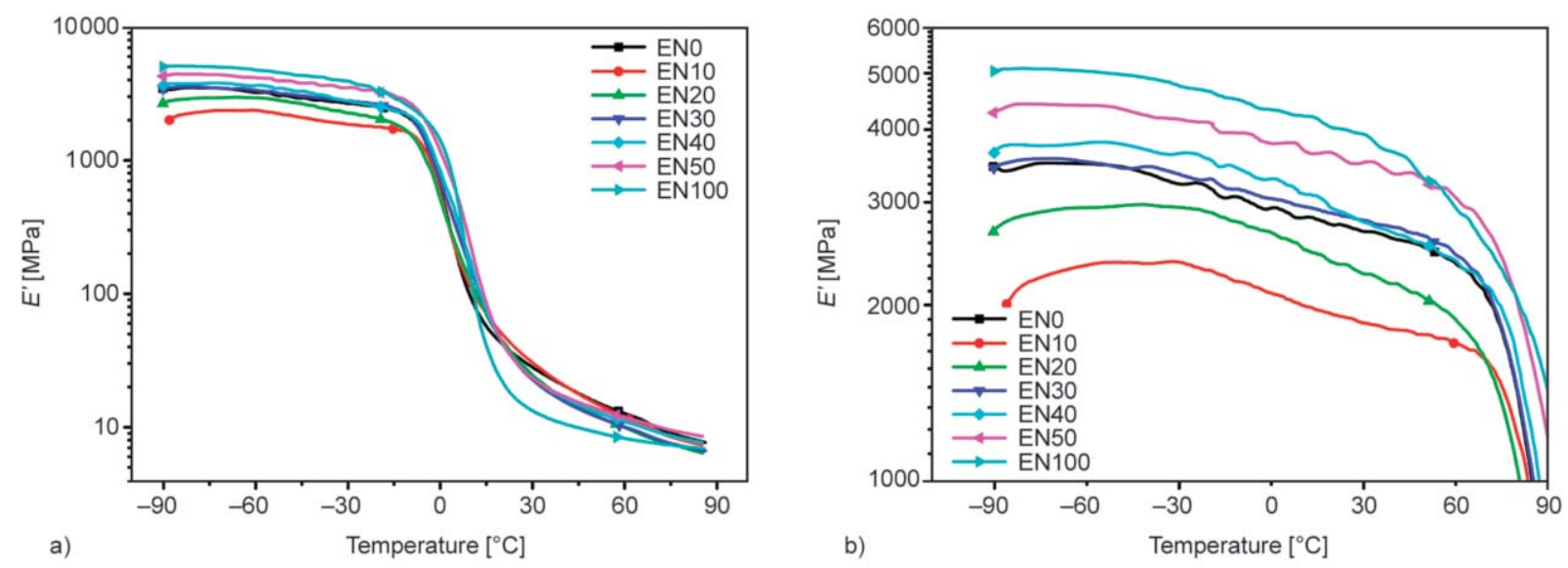

Figure 13. Temperature dependence of the $E^{\prime}$ of the EVM/NBR composites with different NBR content, (a) original, (b) magnification.

L1 NBR content. It can be clearly seen from Figure $13 \mathrm{~b}$ that the $E^{\prime}$ obviously decreases from -90 to $-30{ }^{\circ} \mathrm{C}$ with 10 phr of NBR. When the NBR loading exceeds $10 \mathrm{phr}$, the $E^{\prime}$ gradually increases. Firstly, EVM and NBR separately belong to continuous and dispersed phase, which leads to the decrease of $E^{\prime}$ owing to the less restricted NBR molecular. It is not easy to adjust the relative segment position because of the ascent of crosslink density with the increment of NBR content, which prevents the segments from moving. It is difficult to make EVM and NBR be fully compatible by ordinary blending because of the great polarity discrepancy. Here, DMA was employed to explore the compatibility of EVM/NBR composites prepared by the two-step blending method. Figure 14a and Table 6 show the relationship between the $\tan \delta$ and temperature. It can be clearly found that the glass transition temperature $T_{\mathrm{g}}$ of pristine EVM and NBR are -1.8 and $13.5^{\circ} \mathrm{C}$, respectively. The EVM/NBR composites appear only one $T_{\mathrm{g}}$ peak and the $T_{\mathrm{g}}$ are between -1.8 and $13.5^{\circ} \mathrm{C}$ with sharp peak

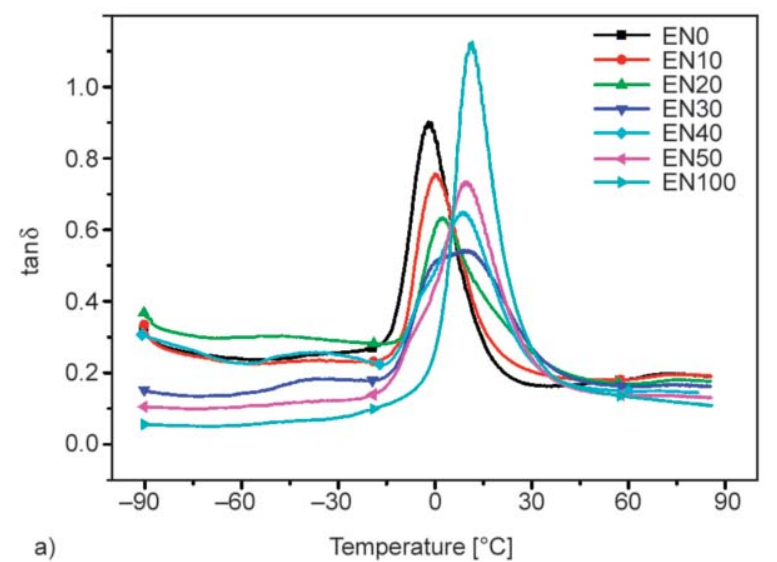

shape of the composites. As the NBR content increases, the $T_{\mathrm{g}}$ is gradually closer to $13.5^{\circ} \mathrm{C}$. So the EVM/NBR composites possess good compatibility prepared by the two-step blending. In addition, the $\tan \delta$ peaks are lower than that of pristine EVM. This is ascribed to the increment of crosslinking density restricting the movement of molecular chain. So there is a great improvement of the wear and oil resistance. The $\tan \delta$ peak shape of EN30 is wider, which possibly results from the increment of effective NBR volume fraction and a good filler-rubber interface adhesion affected by $30 \mathrm{phr}$ of well dispersed CB. Furthermore, there may be exist the transition of the NBR from the dispersed phase to the continuous phase with $30 \mathrm{phr}$ of NBR. The composites develop a co-continuous state when NBR is more than $30 \mathrm{phr}$, the filler-rubber mutual interaction increases resulting in the rising of $\tan \delta$ peak [36].

As is well-known to all, the $\tan \delta$ at $60^{\circ} \mathrm{C}$ represents the rolling resistance of rubber composites. It can reflect the friction of the vulcanized rubber with the

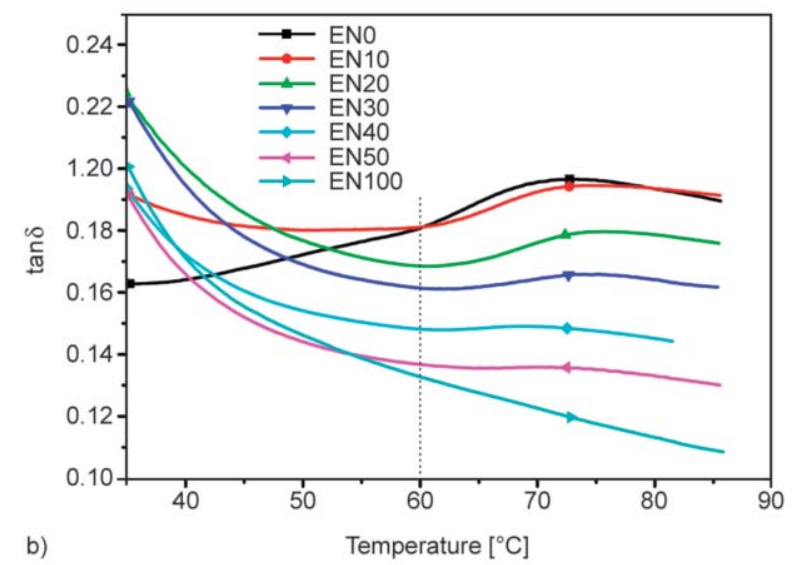

Figure 14. The $\tan \delta-T$ curves of EVM/NBR composites with different NBR content, (a) original, (b) magnification. 
Table 6. Datas of $T_{\mathrm{g}}$ and $\tan \delta$ of EVM/NBR composites.

\begin{tabular}{|l|c|c|c|c|c|c|c|}
\hline Sample codes & EN0 & EN10 & EN20 & EN30 & EN40 & EN50 & EN100 \\
\hline$T_{\mathrm{g}}\left[{ }^{\circ} \mathrm{C}\right]$ & -1.8 & 0 & 1.7 & 9.4 & 11.1 & 11.2 & 13.5 \\
\hline $\tan \delta$ peak & 0.902 & 0.759 & 0.635 & 0.543 & 0.631 & 0.724 & 1.111 \\
\hline $\tan \delta$ at $60^{\circ} \mathrm{C}$ & 0.180 & 0.182 & 0.169 & 0.161 & 0.148 & 0.138 & 0.132 \\
\hline
\end{tabular}

contact surface. It can be seen from Figure $14 \mathrm{~b}$ and Table 6 that $\tan \delta$ progressively decreases with the increment of NBR content to reduce the friction at $60{ }^{\circ} \mathrm{C}$. The reduction of the friction decreases the friction coefficient and improves the wear resistance of the composites. So the the wear resistance of the composites is closely related to its dynamic mechanical properties.

\section{Conclusions}

BIPB crosslinked EVM/NBR composites with excellent wear and oil resistance were fabricated by the simple two-step blending method. The DIN abrasion volume and worn surfaces roughness decreased significantly with the increase of NBR and CB content, which effectively improved the worn surfaces morphology and 3D optical profile. SEM images showed that the wear mechanism of the composites was mainly abrasive wear accompanying with fatigue wear. The vulcanization performances indicated that cocrosslinking occurred between the EVM and NBR by the two-step blending method. The oil resistance rate of volume and weight change were also improved. This can be ascribed to the formation of cocrosslinking and the improvement of crosslink density. It was proved that the EVM/NBR composites had excellent compatibility by the two-step blending method and the wear resistance was closely related to dynamic mechanical properties. The results showed that the increase of polarity and the two-step blending method can boost the rubber-filler interaction to improve the wear and oil resistance of the composites.

\section{Acknowledgements}

All the authors are grateful to the Science and Technology Project of Guangdong Province (2017B090907029) and the Science and Technology Innovation Project of Foshan (2016AG101581) for financial supports.

\section{References}

[1] Shi X., Liu J., Zhao S.: Properties and structure of dynamically vulcanized TPU/EVM blends. Journal of Macromolecular Science Part B: Physics, 48, 12631274 (2009).

https://doi.org/10.1080/00222340903275362

[2] Rybiński P., Janowska G., Plis A.: Thermal properties and flammability of ethylene-vinyl acetate rubbers (EVM) and their cross-linked blends with nitrile rubber (NBR). Thermochimica Acta, 568, 104-114 (2013). https://doi.org/10.1016/j.tca.2013.06.026

[3] Razavi-Nouri M., Karami M.: Effect of rubber content on morphology and thermal and rheological behaviors of acrylonitrile-butadiene rubber/poly(ethylene-co-vinyl acetate)/organoclay nanocomposites. Polymer, 55, 69406947 (2014).

https://doi.org/10.1016/j.polymer.2014.10.050

[4] Shi X. Y., Bi W., Zhao S.: Study on the damping of EVM based blends. Journal of Applied Polymer Science, 120, 1121-1125 (2011). https://doi.org/10.1002/app.33260

[5] Wu W., Wan C., Zhang Y.: Morphology and mechanical properties of ethylene-vinyl acetate rubber/polyamide thermoplastic elastomers. Journal of Applied Polymer Science, 130, 338-344 (2013). https://doi.org/10.1002/app.39046

[6] Liu H., Xiong Y., Xu W., Zhang Y., Pan S.: Synthesis of a novel intumescent flame retardant and its application in EVM. Journal of Applied Polymer Science, 125, 1544-1551 (2012).

https://doi.org/10.1002/app.34924

[7] Osaka N., Kato M., Saito H.: Mechanical properties and network structure of phenol resin crosslinked hydrogenated acrylonitrile-butadiene rubber. Journal of Applied Polymer Science, 129, 3396-3403 (2013).

https://doi.org/10.1002/app.39010

[8] Valentín J. L., Carretero-González J., Mora-Barrantes I., Chassé W., Saalwächter K.: Uncertainties in the determination of cross-link density by equilibrium swelling experiments in natural rubber. Macromolecules, 41, 4717-4729 (2008). https://doi.org/10.1021/ma8005087

[9] Thomas S., Gupta B. R., De S. K.: Tear and wear of thermoplastic elastomers from blends of poly(propylene) and ethylene vinyl acetate rubber. Journal of Materials Science, 22, 3209-3216 (1987).

https://doi.org/10.1007/bf01161184 
[10] Zhang Z. X., Zhang T., Wang D., Zhang X., Xin Z., Prakashan K.: Physicomechanical, friction, and abrasion properties of EVA/PU blend foams foamed by supercritical nitrogen. Polymer Engineering and Science, 58, 673--682 (2018).

https://doi.org/10.1002/pen.24598

[11] Ning N., Hua Y., Wu H., Zhang L., Wu S., Tian M., Tian H., Hu G-H.: Novel heat and oil-resistant thermoplastic vulcanizates based on ethylene-vinyl acetate rubber/poly (vinylidene fluoride). RSC Advances, 6, 91594-91602 (2016). https://doi.org/10.1039/c6ra19335h

[12] Varghese H., Bhagawan S. S., Thomas S.: Effects of blend ratio, crosslinking systems and fillers on the morphology, curing behavior, mechanical properties, and failure mode of acrylonitrile butadiene rubber and poly(ethylene-co-vinyl acetate) blends. Journal of Applied Polymer Science, 71, 2335-2364 (1999).

https://doi.org/10.1002/(SICI)10974628(19990404)71:14<2335::AID-APP7>3.0.CO;2-5

[13] Mostafa A., Abouel-Kasem A., Bayoumi M. R., El-Sebaie M. G.: The influence of CB loading on thermal aging resistance of SBR and NBR rubber compounds under different aging temperature. Materials and Design, 30, 791-795 (2009).

https://doi.org/10.1016/j.matdes.2008.05.065

[14] Pal K., Rajasekar R., Kang D. J., Zhang Z. X., Pal S. K., Kim J. K., Das C. K.: Effect of fillers and nitrile blended PVC on natural rubber/high styrene rubber with nanosilica blends: Morphology and wear. Materials and Design, 31, 25-34 (2010).

https://doi.org/10.1016/j.matdes.2009.07.023

[15] Tangudom P., Thongsang S., Sombatsompop N.: Cure and mechanical properties and abrasive wear behavior of natural rubber, styrene-butadiene rubber and their blends reinforced with silica hybrid fillers. Materials and Design, 53, 856-864 (2014).

https://doi.org/10.1016/j.matdes.2013.07.024

[16] Hong C. K., Kim H., Ryu C., Nah C., Huh Y-I., Kaang S.: Effects of particle size and structure of carbon blacks on the abrasion of filled elastomer compounds. Journal of Materials Science, 42, 8391-8399 (2007).

https://doi.org/10.1007/s10853-007-1795-3

[17] Schallamach A.: Friction and abrasion of rubber. Wear, 1, 384-417 (1958). https://doi.org/10.1016/0043-1648(58)90113-3

[18] Schallamach A.: On the abrasion of rubber. Proceedings of the Physical Society Section B, 67, 883-891 (1954). https://doi.org/10.1088/0370-1301/67/12/304

[19] Thavamani P., Khastgir D.: Compatible blends of ethylene-vinyl acetate copolymer and hydrogenated nitrile rubber. Advances in Polymer Technology, 23, 5-17 (2010).

https://doi.org/10.1002/adv.10066
[20] Bhuyan B., Srivastava S. K., Pionteck J.: MWCNT/ Hectorite hybrid filled acrylonitrile butadiene rubber/ ethylene-co-vinyl acetate blend nanocomposites: Preparation and properties. Journal of Polymer Research, 24, 150/1-150/10 (2017).

https://doi.org/10.1007/s10965-017-1309-1

[21] Shi X. Y., Bi W. N., Zhao S. G.: DMA analysis of the damping of ethylene-vinyl acetate/acrylonitrile butadiene rubber blends. Journal of Applied Polymer Science, 3, 2234-2239 (2012).

https://doi.org/10.1002/app.35301

[22] Shi X., Bi W.: Damping properties of ethylene-vinyl acetate rubber/nitrile butadiene rubber blends. Journal of Macromolecular Science Part B: Physics, 50, 417-426 (2010).

https://doi.org/10.1080/00222341003772266

[23] Liu L., Jia D., Luo Y., Guo B.: Preparation, structure and properties of nitrile-butadiene rubber-organoclay nanocomposites by reactive mixing intercalation method. Journal of Applied Polymer Science, 100, 1905-1913 (2006).

https://doi.org/10.1002/app.22614

[24] Flory P. J., Rehner J.: Statistical mechanics of crosslinked polymer networks I. Rubberlike elasticity. The Journal of Chemical Physics, 11, 512-520 (1943). https://doi.org/10.1063/1.1723791

[25] El-Nemr F. K.: Effect of different curing systems on the mechanical and physico-chemical properties of acrylonitrile butadiene rubber vulcanizates. Materials and Design, 32, 3361-3369 (2011).

https://doi.org/10.1016/j.matdes.2011.02.010

[26] Lindvig T., Michelsen M. L., Kontogeorgis G. M.: A Flory-Huggins model based on the Hansen solubility parameters. Fluid Phase Equilibria, 203, 247-260 (2002). https://doi.org/10.1016/S0378-3812(02)00184-X

[27] Liang H., Fukahori Y., Thomas A. G., Busfield J. J. C.: The steady state abrasion of rubber: Why are the weakest rubber compounds so good in abrasion? Wear, 268, 756-762 (2010).

https://doi.org/10.1016/j.wear.2009.11.015

[28] Schallamach A.: Abrasion of rubber by a needle. Journal of Polymer Science, 9, 385-404 (1952).

https://doi.org/10.1002/pol.1952.120090501

[29] Asaad J. N., Mansour S. H., Abd-El-Messieh S. L.: Some studies on poly(ethylene-co-vinyl acetate), acrylonitrile butadiene copolymer, and their blend reinforced with carbon black. Journal of Reinforced Plastics and Composites, 32, 1634-1645 (2013). https://doi.org/10.1177/0731684413497414

[30] Valentín J. L., Rodríguez A., Marcos-Fernández A., González L.: Dicumyl peroxide cross-linking of nitrile rubbers with different content in acrylonitrile. Journal of Applied Polymer Science, 96, 1-5 (2005). https://doi.org/10.1002/app.20615 
[31] Chen S., Zhang Y., Wang R., Yu H., Hoch M., Guo S.: Mechanical properties, flame retardancy, hot-air ageing, and hot-oil ageing resistance of ethylene-vinyl acetate rubber/hydrogenated nitrile-butadiene rubber/magnesium hydroxide composites. Journal of Applied Polymer Science, 114, 3310-3318 (2009).

https://doi.org/10.1002/app.30620

[32] Zou H., Sun J., Gu X-Y., Jiang P., Liu X-S., Zhang S.: Preparation and characterization of flame retardant and low smoke releasing oil-resistant EVA/NBR blends. Chinese Journal of Polymer Science, 33, 554-563 (2015). https://doi.org/10.1007/s10118-015-1606-2

[33] Ma P., Xu P., Liu W., Zhai Y., Dong W., Zhang Y., Chen M.: Bio-based poly(lactide)/ethylene-co-vinyl acetate thermoplastic vulcanizates by dynamic crosslinking: Structure vs. property. RSC Advances, 5, 15962-15968 (2015).

https://doi.org/10.1039/C4RA14194F
[34] Li S., Liu T., Wang L., Wang Z.: Dynamically vulcanized nitrile butadiene rubber/ethylene-vinyl acetate copolymer blends compatibilized by chlorinated polyethylene. Journal of Macromolecular Science Part B: Physics, 52, 13-21 (2013). https://doi.org/10.1080/00222348.2012.687255

[35] Loan L. D.: Peroxide crosslinking of ethylene-propylene rubber. Journal of Polymer Science Part A, 2, 3053-3066 (1964). https://doi.org/10.1002/pol.1964.100020704

[36] Ma J., Shao L., Xue C., Deng F., Duan Z.: Compatibilization and properties of ethylene vinyl acetate copolymer (EVA) and thermoplastic polyurethane (TPU) blend based foam. Polymer Bulletin, 71, 2219-2234 (2014). https://doi.org/10.1007/s00289-014-1183-5 